\title{
A framework for monitoring transition systems
}

Citation for published version (APA):

van der Velden, R. K. W., \& Wolbers, M. H. J. (2006). A framework for monitoring transition systems. Researchcentrum voor Onderwijs en Arbeidsmarkt, Faculteit der Economische Wetenschappen. ROA Reports No. 9E https://doi.org/10.26481/umarep.200609E

Document status and date:

Published: 01/01/2006

DOI:

10.26481/umarep.200609E

Document Version:

Publisher's PDF, also known as Version of record

\section{Please check the document version of this publication:}

- A submitted manuscript is the version of the article upon submission and before peer-review. There can be important differences between the submitted version and the official published version of record.

People interested in the research are advised to contact the author for the final version of the publication, or visit the DOI to the publisher's website.

- The final author version and the galley proof are versions of the publication after peer review.

- The final published version features the final layout of the paper including the volume, issue and page numbers.

Link to publication

\footnotetext{
General rights rights.

- You may freely distribute the URL identifying the publication in the public portal. please follow below link for the End User Agreement:

www.umlib.nl/taverne-license

Take down policy

If you believe that this document breaches copyright please contact us at:

repository@maastrichtuniversity.nl

providing details and we will investigate your claim.
}

Copyright and moral rights for the publications made accessible in the public portal are retained by the authors and/or other copyright owners and it is a condition of accessing publications that users recognise and abide by the legal requirements associated with these

- Users may download and print one copy of any publication from the public portal for the purpose of private study or research.

- You may not further distribute the material or use it for any profit-making activity or commercial gain

If the publication is distributed under the terms of Article $25 \mathrm{fa}$ of the Dutch Copyright Act, indicated by the "Taverne" license above, 


\section{A Framework for Monitoring Transition Systems}

Rolf K.W. van der Velden

Maarten H.J. Wolbers

ROA-R-2006/9E 


\section{Colophon}

(C) Research Centre for Education and the Labour Market. No part of this publication may be reproduced without the prior permission in writing of the director of the Research Centre for Education and the Labour Market.

\section{Research Centre for Education and the Labour Market}

Faculty of Economics and Business Administration

Maastricht University

Layout

Secretary ROA, Maastricht

\section{Sales}

Research Centre for Education and the Labour Market email: secretary@roa.unimaas.nl

website: www.roa.unimaas.nl

ISBN-IO: 90-532I-448-8

ISBN-I3: 978-90-532I-448-O

November 2006 


\section{Contents}

1 Introduction

2 Results of the Network B quick scan on transition policy goals 3

3 A theoretical framework for monitoring transition systems $\quad 7$

4 A reformulation of policy goals in the light of the developed framework

5 Empirical indicators for monitoring transition systems

5.1 Introduction

5.2 Some definition issues 23

5.3 Empirical indicators for each dimension 25

5.3.1 Indicators for the education system 25

5.3.2 Indicators for the transition system 30

5.3.3 Indicators for the employment system 36

5.3.4 Indicators for the contextual factors 37

6 Evaluation and further strategy 39

$\begin{array}{ll}\text { References } & 43\end{array}$

Appendix A: Description of data sources $\quad 47$

Appendix B: Relevant questions from EULFS and ECHP 49

Appendix C: Comparison of age groups, synthetic cohorts and real cohorts $\quad 57$

Appendix D: Comparison of unemployment rates for lower educated and higher educated 65

Appendix E: Comparison of two measures of graduation rates $\quad 67$ 



\section{Introduction}

With its publication of the Thematic Review on the Transition from Initial Education to Working Life in 2000, OECD has laid the foundation for the development of indicators regarding the transition from education to work. One of the core activities of OECD's Network B in 2005 and 2006 is to further develop these indicators by establishing a framework for monitoring transition systems. To establish this framework, the following steps need to be taken:

1. To analyse (and update) the earlier defined transition policy goals, in particular those put forward in the Thematic Review on Transition from Initial Education to Working Life;

2. To develop a theoretical framework to monitor transition systems;

3. To develop a set of international comparable indicators for monitoring transition systems;

4. To identify possible data sources for measuring these indicators (e.g. Labour Force Surveys, other survey data, register data);

5. To define a research strategy to analyse the indicators from a cross-national perspective.

A first step towards the establishment of a framework for monitoring transition systems was accomplished with the Network B quick scan of policy goals for transition systems and relevant indicators used to assess national situations (November 2002-January 2003). An overview of the results of this quick scan will be given in section 2.

The next step was the development of a theoretical framework for the analysis of transition systems. In section 3 a theoretical framework is presented that identifies the most relevant characteristics of transition systems. It also relates the outcomes of the transition system to relevant characteristics of the educational system on the one hand and the employment system on the other hand.

Section 4 then continues with an evaluation of the earlier defined policy goals, taking into account the results of the above-mentioned quick scan and the developed theoretical framework. We identified a total of II policy goals. Where necessary, we changed the formulation of some of the original policy goals to make them less ambiguous. 
As a third step, we have analysed the existing data sources from OECD, EUROSTAT and major international surveys, to identify relevant indicators for the policy goals as well as descriptors for relevant other aspects of the developed framework. Section 5 will present an overview of these indicators and descriptors.

The theoretical framework and the developed set of indicators have been discussed at the March 2006 meeting of the Network B in Washington DC. Members of the network have also sent written comments. All these comments have been taken up in this final version.

In section 6 we will briefly summarise and evaluate the developed framework and elaborate a publication strategy and a research strategy for future data collection and data analysis by Network B. 


\section{Results of the Network B quick scan on transition policy goals}

In the Thematic Review seven policy goals have been suggested that all national transition policies should aim for (OECD, 2000: IO). These include:

1. High proportions of young people completing a full upper secondary education with a recognised qualification for work, tertiary study or both;

2. High levels of knowledge and skills among young people at the end of the transition phase;

3. A low proportion of teenagers being at the one time not in education and unemployed;

4. A high proportion of those young adults who have left education having a job;

5. Few young people remaining unemployed for lengthy periods after leaving education;

6. Stable and positive employment and educational histories in the years after leaving upper secondary education;

7. An equitable distribution of outcomes by gender, social background and region.

In addition, fourteen indicators have been defined to assess performance with respect to these goals. The following indicators have been formulated (within brackets we refer to the goal):

1. Per cent not in education one year after the end of compulsory schooling (goal I);

2. Per cent of 20-24-year-olds whose highest level of education is lower secondary school (ISCED o-2) (goal I);

3. Apparent upper secondary graduation rates (goal I);

4. Per cent of 25-29-year-olds with tertiary qualifications (goal 2);

5. Per cent of I6-25-year-olds at document literacy level 4/5 (goal 2);

6. Non-student unemployed as a per cent of all 15 -19-year-olds (goal 3);

7. Unemployment to population ratio, I5-19-year-olds (goal 3);

8. Unemployment to population ratio, 20-24-year-olds (goal 3);

9. Ratio of the unemployment rate among $15-24$-year-olds to the unemployment rate among 25-64-year-olds (goal 3);

10. Per cent of non-students employed, age 20-24 (goal 4); 
11. Employment to population ratio, 20-24-year-olds (goal 4);

12. Per cent of unemployed I5-I9-year-olds unemployed for six months or more (goal 5);

13. Per cent of unemployed 20-24-year-olds unemployed for six months or more (goal 5);

14. Ratio of low qualified 20-24-year-olds' share of total unemployment to their share of total employment (goal 7).

The overview makes clear that for most goals indicators have been formulated. The sixth goal however, concerning stable and positive employment and educational histories, has no direct indicator.

Together, these transition policy goals and related indicators have laid the foundation for the establishment of a framework for monitoring transition systems. However, to further develop this framework, it is necessary to revalidate the policy goals and ensure that they are still relevant for policy-making. Therefore, a survey to review national policy goals and indicators has been sent out to all Network B members at the end of 2002. They were asked to gather and report the appropriate information for their specific country needed to answer the questions stated in this quick scan. The questions refer to the policy goals, data and transition indicators. Concerning the policy goals, three questions were formulated:

1. What are the stated goals of policies developed and implemented in your country with respect to school-to-work transitions?

2. Are the goals proposed in the Thematic Review an appropriate reflection of those adopted for guiding the policy development on transition in your country?

3. Are there other or different goals set in your country which should be reflected in the development of a monitoring system of transitions, through internationally comparable indicators?

With respect to the first question, most network members gave pretty detailed information on the policy actions taken in their country with respect to school-to-work transitions. In most countries, the general aim of their policies is to smooth the transition from school to work, although different choices of wording are used to formulate this aim. A few examples are:

- Well-prepared learners for the world of work (Canada - Alberta);

- Ensuring youth make successful transitions from school to work (Canada - New Foundland);

- Improved transitions of young people (Australia);

- Initial educational system should make sure that level of youngsters leaving education insufficiently qualified is kept as low as possible (Belgium Flanders);

- Professional integration (Belgium - the Walloon provinces); 
- Quality of training should be such that the vocational skills of the graduated young people are relevant and proper for the working life (Finland);

- A stronger link between school and the labour market (Italy);

- Young people shall be well prepared to live a good independent life (Sweden).

The network members of some countries, however, gave quite different answers. In Denmark, for instance, the main goal is to ensure that young people finish their studies faster in order to increase the workforce. And in Germany, the policy strategy concerning school-to-work transitions pursues structural improvements in co-operation with companies, social partners and schools. According to the reactions of the network members, no explicit policy goals are formulated in Hungary, Luxembourg, Norway and Spain.

With regard to the second question, the answers given by the network members, point even more in the same direction. Overall, the goals proposed in the Thematic Review seem appropriate. Two network members remark that the policy goals set out in the Thematic Review are more specifically targeted than the goals defined in their countries (Canada - Saskatchewan, Sweden).

This general consensus about the national appropriateness of the policy goals does not mean that the goals proposed in the Thematic Review are considered as complete. In answering the third question, some network members came up with additional goals that should be taken into account when developing a comprehensive framework for monitoring transition systems. First of all, a goal regarding adult learning was mentioned by various network members. From the Canadian point of view, the goals proposed in the Thematic Review are incomplete, as they primarily address goals related to youth and adults in transition from school to work, and not those related to adults who are returning to training or work. In Canada, the stated policy goal is to ensure that every student realizes his/her potential not only through formal education, but also through continuous learning. Moreover, the transition from school-to-work is viewed there as continuous in nature, rather than a process with an end point. Hence, a lifelong learning culture is promoted in Canada. In Belgium - Flanders, lifelong learning measures are explicitly embedded in and aimed for by the employment and transition policy. Participation in lifelong learning programmes is considered there as a key condition in the process of acquiring or keeping an appropriate job. Also in Belgium - the Walloon provinces, the possibilities of lifelong learning are enhanced. In Germany, the education policy strategy concerning school-to-work transitions is funding projects to prepare students for working life and to strengthen their employability. In Sweden, a wide-spread system for lifelong learning is developed to promote economic growth and a fair distribution of education and economic welfare generally, and to provide qualifications for young people that promote employability specifically. New Zealand aims at sustainable employment outcomes for young people including 
working conditions and training/development opportunities whilst in employment, that are consistent with the lifelong learning approach.

Second, promoting interaction between the education system and the employment system was reported as a goal which should be reflected in the development of a framework for monitoring transition systems. In Sweden, for instance, the difference between students from theoretical and vocational programmes in upper secondary education (apprenticeships, school-based vocational training, workplace-based vocational training) is an important policy issue. To achieve this, in the area of educational policy, a specific goal is formulated to integrate communication between educational institutions and the labour market in education and research. In Belgium - Flanders, co-operation with private companies is sought through regional technological centres (RTC's). These institutions are set up to facilitate contacts between private companies and schools. They are supposed to come to agreements in which is stipulated that a company will allow a (technical or vocational) school to use its infrastructure and equipment, school teachers can come to the work floor to enhance their professional experience and students are welcome to fulfil their necessary apprenticeships. In this way, students can get work experience, the skills and knowledge of teachers are kept up to date and it can become clear(er) to the schools and the students which skills and competencies are required. In New Zealand, the desire to a better coordination between education and the labour market is reflected in a policy goal that aims at achieving a coherent transition system, including better coordination of services for young people at risk, and alignment of services, institutions, agencies, and policy frameworks. In Germany, the policy strategy concerning school-to-work transitions pursues structural improvements in co-operation with companies, social partners and schools. And also in Hungary, efforts are made to strengthen the co-operation between education and the economy.

Third, a number of network members (from Australia, Belgium, Hungary and New Zealand) proposed to add young people from ethnic minority groups and those with disabilities as particular target groups for which an equitable distribution of outcomes is desired. Therefore, as the Australian network member suggests, the seventh and last goal formulated in the Thematic Review should relate more to equitable opportunities for all young people rather than equitable outcomes for particular target groups.

The main conclusion that can be drawn from this quick scan is that most of the original policy goals are still valid. The suggestion is made to change the seventh goal such that it relates more to equitable opportunities for all young people rather than equitable outcomes for particular target groups. Moreover, some network members have suggested adding policy goals on the importance of adult learning, access to tertiary education and the strengthening of the co-operation between schools and employers. We will get back to this issue after the elaboration of the theoretical framework. 


\section{A theoretical framework for monitoring transition systems}

In listing the set of indicators, we already grouped them according to the specific policy goal that they are supposed to reflect. The advantage of grouping different indicators by policy goals is that there is a clear relation between the formulated policy goals and the indicators that try to evaluate these goals. A drawback of this approach might be that not all aspects that are relevant for a well functioning of the transition system are clearly reflected in the policy goals. Sometimes, relevant aspects of a transition system are taken for granted. Moreover, stated policy is very sensitive to changes in the political climate. This means that policy goals - and the related indicators - may change over time. It may therefore be helpful to incorporate these policy goals in a broader theoretical framework that tries to identify the different aspects of a transition system. Such a framework enables us to see if there are any blind spots either in the formulated policy goals or in the developed indicators.

The Thematic Review has already highlighted a set of key ingredients of successful transition systems:

1. A healthy economy;

2. Well organised pathways that connect initial education with work and further study;

3. Widespread opportunities to combine workplace experience with education;

4. Tightly knit safety nets for those at risk;

5. Good information and guidance; and

6. Effective institutions and practices.

Also relevant are the policy issues that have been identified in the Helsinki 2005 Network B strategy paper. This strategy paper identified six relevant policy areas and recommends developing indicators in each of these areas:

1. What is the impact of different levels and types of education, including leaving school without graduating, on the labour market outcomes of young people? Which educational pathways lead to which labour market outcomes? How are new entrants with different educational backgrounds integrated into the workforce? 
2. How does the nature of educational programmes and choices affect transition processes? What educational, labour market and social policies result in more effective transition outcomes for young people?

3. How do educational and labour market pathways vary for different groups of youths? Relevant groups would include: males and females, those from ethnic minorities, lower socio-economic backgrounds, or with learning disabilities. Which young people have difficulty making the transition and face a greater risk of unemployment or social exclusion? What policies prevent the negative effects of different backgrounds or help compensate for them?

4. What policies and programmes support successful transitions? Examples include guidance, counselling, labour market information systems.

5. How can the transition process be organised to promote lifelong learning? How can young people be encouraged to engage in further learning beyond initial schooling? How can employers be supportive of young people's further skill development through access to training opportunities?

6. How is the balance in OECD countries between the number of graduates and the supply of skills in the labour market? The demographic structure in the member countries implies risks of a lack of staff in several sectors of the labour market. What roles do education and transition systems play in addressing challenges imposed by the demographic trends and rapid changes in job demands in a constantly evolving working environment?

All of these factors will be taken into account in the wider framework that we will develop.

Before we can elaborate the relevant characteristics of a transition system, it is useful to look at the transition process from a micro-perspective: How does the transition process look from the perspective of an individual making the transition or the employer offering a job? Figure $\mathrm{I}$ is an elaboration of a framework presented in the Report of the Task Force on Transition into Employment of the Canadian Labour Force Development Board (CLFDB, 1994) and gives a schematic overview of the main factors affecting the transition process. The left hand side represents the supply on the labour market, individuals with a set of personal characteristics. The right hand side represents the demand side, employers offering jobs. Both supply and demand are affected by characteristics that are not under the direct control of the individual or the employer (the boxes in the upper left and right corner). The boxes in the lower corners represent factors affecting the supply and demand that are the result of decisions made by the individual or the employer. The boxes in the middle represent the transition system. The outcomes of the transition process can be studied both from a quantitative point of view (does an individual find work; does an employer fulfil his/her vacancy?) and from a qualitative point of view (is there a match in terms of relevant individual and job characteristics). This transition process is in turn affected by factors under the control of the individual or employer (search behaviour, selec- 
tion and hiring practices) as well as by institutional factors beyond the control of the individual or employer (transparency of the labour market, support mechanisms).

\section{Figure 1}

The transition process from a micro-perspective (based to a large extent on CLFDB, 1994)

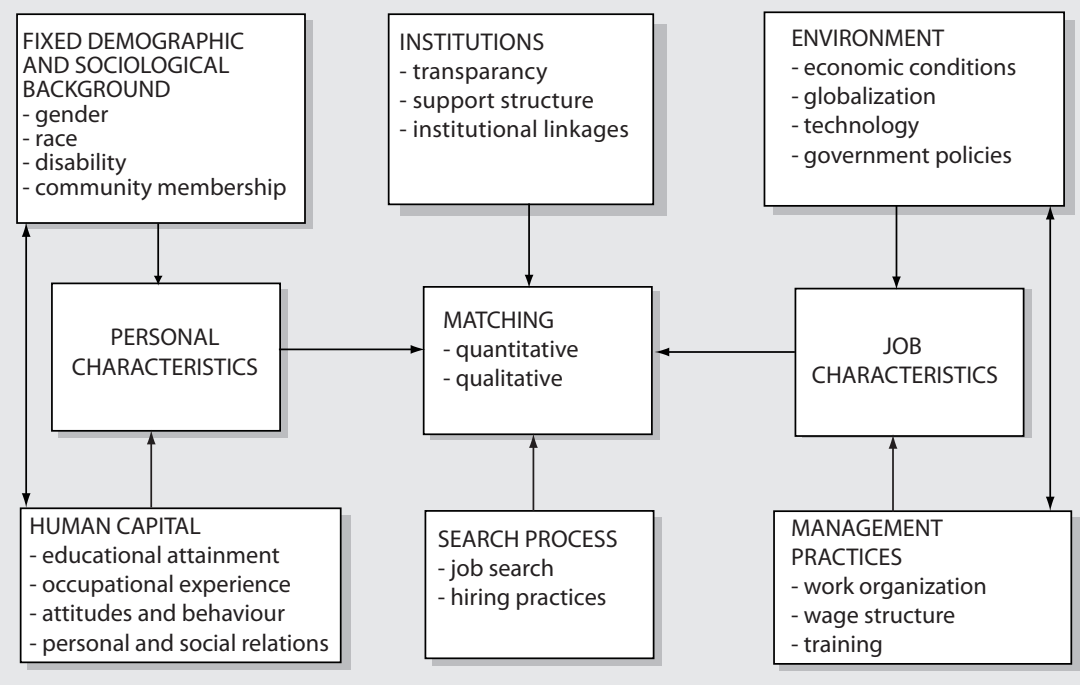

For the purpose of monitoring different transition systems, we need to shift the focus from the micro-perspective to the macro-perspective (see figure 2). How do individual transitions translate into macro-level outcomes and what are the main institutional and socio-economic factors that frame and shape this transition process? A transition system is here defined as "the social institutions and processes through which a society provides its members to make the transition from the education system to the employment

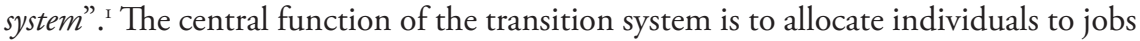
in such a way that an optimal match between supply and demand is reached.

In terms of outcomes we can distinguish the following dimensions:

1. A quantitative dimension relating to the employment chances for individuals who make the transition from school to work;

2. A qualitative dimension referring to the realised matches between supply and demand. Even in the case of a perfect quantitative balance between supply and demand, the actual match at the micro level may be far from optimal. School-leavers may end up in jobs for which they are overqualified or which

I. A transition system is part of a wider concept of 'labour market'. It is not quite clear for us when the term was first introduced. In the Thematic Review (OECD, 2000) it was already used, but not defined. It seems that the main reason for using this concept instead of the broader concept of labour market, is the wish to focus on those labour market aspects that relate most directly to the transition from school to work. The concept of labour market also includes the perspective of employers trying to fill vacancies or the search processes at a later point of the occupational career. 
otherwise do not meet their demands, and they will incur additional costs to improve the match;

3. The third dimension cutting across the other two is equity. This relates to the policy goal that the distribution of outcomes across individuals should be the same for all relevant equity groups: gender, social and ethnic background, educational group etc.

Figure 2

The transition process from a macro-perspective

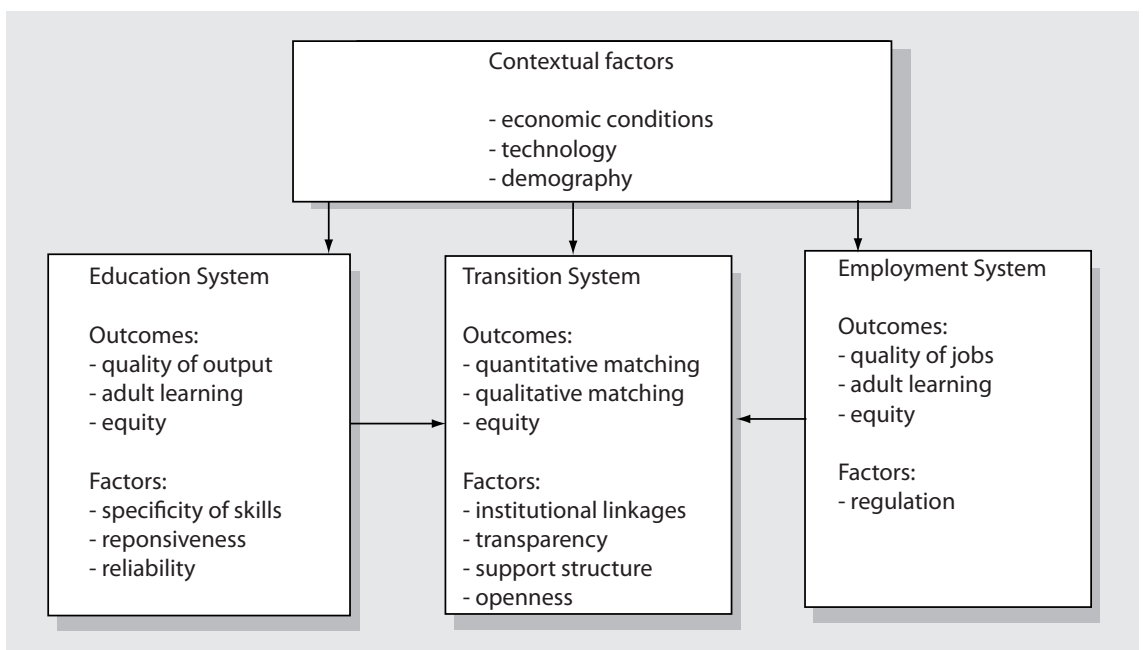

Apart from these dimensions related to outcomes, we can distinguish the following structural and institutional factors in transition systems that affect these outcomes: institutional linkages, transparency, support structure and openness.

4. Institutional linkages between the educational system and the employment system and flexibility of pathways (Müller and Gangl, 2003) improve the smoothness of the transition process. Historically the separation of the educational system and employment system caused the emergence of a transition system. In cases where the two are still strongly interlinked, such as in the dual system, the transition process is much smoother than in cases where the two systems are completely disconnected (Hannan et al., 1996; OECD, 2000; Ryan, 200I). More in general, the OECD Thematic review concluded that 'well organised pathways that connect initial education with work' and 'widespread opportunities to combine workplace experience with education' are key ingredients for a successful transition system (OECD, 2000: 15, I7).

5. Individuals and employers have to make decisions on job offers or job applicants under incomplete information. Part of the high mobility rates in the transition phase is explained by the fact that initial matches have been based on partial information. Increasing the transparency of the transition system by offering reliable and easy accessible information on job offers and educational 
courses helps to improve the matching between individuals and jobs. Good information and guidance practices are therefore important (OECD, 2000: I8).

6. Transitions systems differ in the extent they provide direct support to suppliers of labour to find a job or to employers to find a job holder (Ryan, 200I). The support that institutions offer may vary from general support to Active Labour Market Programs aimed for specific groups at risk. As the Thematic review concluded: tightly knit safety nets for those at risk are key to successful transition systems (OECD, 2000: I8).

7. Transition systems differ in the degree of openness that is in the degree to which they give the same employment opportunities for newcomers as for the existing labour force. This is partly affected by the degree of regulation of the employment system (see below). In an employment system characterised by a high degree of employment protection for existing employees, newcomers on the labour market will find it more difficult to 'fight' their way in. Another aspect of openness relates to the ease with which people can start their own business. Self-employment can be seen as an important alternative for finding salaried work on the labour market.

In turn, the well-functioning of this transition system is affected by the functioning of two other systems: the educational system and the employment system. The educational system (including not only initial education but also further training) is responsible for the supply of relevant skills, while the employment system is accountable for the demand for labour. For both systems we would like to distinguish a number of dimensions that are likely to affect the quality of the supply respectively the demand on the labour market both in terms of outcomes as in terms of relevant structural and institutional factors.

The following three dimensions seem relevant with respect to the outcomes of the educational system:

1. Quality of output: Educational systems differ in the quality and the level at which skills are produced. There is a long research tradition specifying that one of the main mechanisms through which education affects labour market outcomes is by increasing the productive skills of students (Becker, 1964). Others have argued that schooling does not necessarily increase the direct productivity of students (Thurow, I975), but 'signal' a high learning ability (Spence, 1973), thereby decreasing the expected training costs.

2. Adult learning: Educational systems differ in the opportunities they offer to return to education at later points in the career. As a result of technological changes or changes in the occupational career, skills may become obsolete (Van Loo et al., 200I), leading to a decline in the productivity. Educational systems that are open and offer good opportunities for adult learning are better equipped to deal with these changes. 
3. Equity: The extent to which the outcomes of the educational system are equally distributed across the different relevant social groups (gender, social and ethnic background etc).

Relevant institutional factors of the educational system are:

4. Specificity of skills: Educational systems differ in the kind of skills that they produce. Some educational systems produce mainly vocational specific skills that can directly be used at the workplace; others offer a variety of generic skills that may have to be supplemented by additional training on-the-job. The effect on the transition process may be different. On the one hand employers may favour specific skills over generic skills, because of the higher direct productivity. On the other hand, generic skills are more and more valued on the labour market as well, partly because it increases the overall employability of school-leavers, partly because rapid technological developments may turn specific skills obsolete. Moreover, high specificity of acquired and required skills may induce a longer search process.

5. Responsiveness: Educational systems may differ in the degree to which they react to changes in the requirements on the labour market. Given the 'production time' in education, the educational system has to prepare for the requirements in the labour market in four or five years time. Given the nature of the skills involved, vocational oriented systems are especially vulnerable for the risk of producing the wrong skills and need a high degree of responsiveness.

6. Reliability: Employers have incomplete information about the 'true' skills of applicants. They will therefore use screening devices like education followed as an indicator of these skills (Spence, 1973). The problem is that education does not produce a homogeneous good. Even within a specific level of education there is still a large variation in individual quality, with students achieving below and above particular standards (Glebbeek, 1988). Therefore the reliability of the educational signal greatly affects the role of educational credentials on the labour market. This reliability in turn is affected by the standardisation and stratification of the educational system (Allmendinger, 1989). Stratification refers to the vertical and horizontal differentiation of the educational system and standardisation refers to whether exams, curricula etc. meet the same standards nationwide.

We can distinguish some similar dimensions when we look at the outcomes of the employment system:

1. Quality of jobs: Employment systems differ in the quality and level of the jobs they produce. Although the Skill Biased Technological Change refers to a general tendency of increasing skills requirements, some systems are trapped in a 'low-skills equilibrium' (Finegold \& Soskice, 1988; Keep \& Mayhew, I998). The quality of the job is reflected in the level of the required skills, but also in the job security, wages and career prospects. 
2. Adult learning: Employment systems differ in the extent to which they provide good training and learning possibilities for further skills development. Especially in situations where rapid changes in the skill requirements take place as a result of technological change or organisational changes, keeping the existing stock of skills up-to-date is of vital importance. Employers can 'buy' these skills on the labour market or they can 'make' them self. Offering good training and learning possibilities reduces the pressure to buy these skills on the labour market.

3. Equity: The extent to which outcomes of the employment system are equally distributed across the different relevant social groups (gender, social and ethnic background, educational group etc).

We distinguish the following institutional factor of the employment system:

4. Employment systems differ in the degree of regulation (Hartog \& Theeuwes, 1993; Esping-Andersen \& Regini, 2000; Ryan, 200I) and the extent to which they protect the interests of the insiders (i.e. the existing personnel, Lindbeck \& Snower, 1988). Access to certain occupations and professions may be subject to strict rules and entry requirements, making it more difficult for outsiders to enter these segments. Regulation may also pertain to employment conditions like minimum youth wages or working hours.

Finally, the outcomes in the transition system, as well as the education and employment system are affected by a number of contextual factors. These structural and institutional factors determine the macro level opportunity structure that shapes and constraints the interactions at the micro level between graduates and employers. We distinguish the following dimensions:

1. Economic conditions: The Thematic Review pointed out quite clearly that 'a well functioning economy is perhaps the most fundamental factor to shape young people's transition from initial education to work' (OECD, 2000: I3). It goes without saying that national wealth and economic growth are key factors in determining investments in education as well as in the employment system. Moreover, new entrants to the labour market are more affected by ups and downs in the business cycle than the existing labour force.

2. Technology: Developments in technology greatly determine the demand for skilled labour. The term 'Skill Biased Technological Change' is used to indicate the effect technological change has on a wide range of required skills (Machin \& Van Reenen, 1998; Caroli \& Van Reenen, 200I). These studies generally point to trends of increasing complexity of work or upgrading (Borghans \& De Grip, 2000) and accelerating obsolescence of existing skills (De Grip \& Van Loo, 2002).

3. Demography: Demographic developments have major impacts on the three systems. They are primary determinants of the inflow and outflow of the educational system and thus on the overall supply of skills labour. Moreover, ageing determines the outflow of the employment system as well, thus deter- 
mining the replacement demand on the labour market. Finally, relative youth cohort size has a pronounced effect on the job chances of young people in the labour market (Macunovich, 1999). 


\section{A reformulation of policy goals in the light of the developed framework}

In this section we will map the policy goals to the different aspects of the theoretical framework. This will enable us to give a more solid base to these policy goals and to identify any blind spots. In evaluating these policy goals, it is important to make sure that they are formulated in a way that points to undisputed desirable outcomes. Moreover, they must be formulated such that it is possible to find empirical indicators that clearly show that the policy goals have been reached.

Before we evaluate the earlier formulated policy goals, we have to decide whether policy goals should only be formulated with respect to the outcomes of the transition system or also with respect to the outcomes of the education system or the employment system. Considering that the outcomes of the educational system and the employment system, directly affect the supply and demand on the labour market, and thus the outcomes of the transition system, it makes sense that policy goals should be formulated for all three types of outcomes. This is also in line with the fact that some of the earlier formulated policy goals, clearly relate to the outcomes of the educational system (policy goals I and 2).

A different issue is whether policy goals should be formulated for all factors distinguished in the theoretical framework that affect these outcomes. Although many of these factors are key ingredients for the well-functioning of a transition system, they do not necessarily have to be in place for a system to function well. To give an example, it is clear that support or labour market regulation can affect the matching process on the labour market, but this does not imply that lack of support or a strong regulation is always bad. The economic conditions may be so good that the matching process is good, regardless of the extent of support or regulation. This makes clear that the achievement of the policy goals should be accompanied by an analysis of the various aspects of the contexts in which transitions take place.

Although the factors may be very relevant in explaining why some transition systems are more successful than others, we propose not to formulate any policy goal for them. However, as these factors clearly bear relevance to explain differences in the outcomes of the three systems, we will try to develop empirical descriptors for each of them. 


\section{Outcomes of the education system}

The following policy goals were formulated with respect to the dimension of quality of outcomes of the education system:

- High proportions of young people completing a full upper secondary education with a recognised qualification for work, tertiary study or both;

- High levels of knowledge and skills among young people at the end of the transition phase.

The first goal reflects the broad consensus that a certificate at full upper secondary education level (i.e. ISCED ${ }_{3} \mathrm{~A},{ }_{3} \mathrm{~B}$ or ${ }_{3} \mathrm{C}$ long) is the minimum level to be reached by every student in secondary education. This certificate opens up the possibility for further study at tertiary level or is regarded as a minimum requirement to enter the labour market. Given the growing importance of tertiary education and the notion that increasing the enrolment of tertiary education in order to reach the Lisbon goals, it seems appropriate to add an additional goal reflecting this idea: 'High proportions of young adults completing a tertiary education'.

The second policy goal reflects the idea that it is not the qualification as such, but the underlying skills that count. Young people need to posses the basic skills that are required to function well in the modern knowledge economy. This means a basic level of numeracy, literacy, information processing, problem solving, computer skills, communication skills, social skills etc. What is a bit strange in the way it is now formulated is the addition 'at the end of the transition phase'. It makes more sense to demand that young people need to have these skills when they enter the labour market, rather than to have these skills once they have made the transition. We therefore propose to reformulate this policy goal into: 'High levels of competences among young people when they enter the labour market'.

In the quick scan several members of the Network have suggested to take up a policy goal that stresses the importance of adult learning. On the one hand this relates to creating opportunities for adult learning in the education system, especially for those that have not yet earned a minimum qualification level. On the other hand adult learning also refers to creating learning possibilities outside the education system, especially at work. We propose to formulate the following two policy goals:

- Good opportunities for young adults outside the education system to return to education to study towards a formal upper secondary education degree or higher;

- High proportions of young adults outside the education system having good opportunities to develop their competences.

With respect to equity, we propose to follow the suggestion made in the quick scan and change the original goal ('An equitable distribution of outcomes by gender, social background and region') into the more general: 'An equitable distribution of these 
outcomes for risk groups compared to non-risk groups (e.g. by gender, social and ethnic background etc)'.

\section{Outcomes of the transition system}

The following policy goals were formulated with respect to the dimension of quantitative matching:

- A low proportion of teenagers being at the one time not in education and unemployed;

- A high proportion of those young adults who have left education having a job;

- Few young people remaining unemployed for lengthy periods after leaving education;

- Stable and positive employment and educational histories in the years after leaving upper secondary education.

The first policy goal ('A low proportion of teenagers being at the one time not in education and unemployed') reflects the idea that teenagers should be either in education or at work. We will use the term 'teenagers' to refer to the i5-19-year-olds. However, the way it is now formulated suggests that 'being not in education and unemployed' is the only undesired outcome. But 'being not in education and out of the labour force' is an undesired outcome as well. We propose to change the formulation such that both types of outcomes are included. Moreover, we propose to include the age group of 20-24-year-olds as well (the term 'young people' will be used to refer to the group of I5-24-year-olds and sometimes to the broader group of 15-29-year-olds): 'A low proportion of young people being at the one time not in education and not at work'.

In the case of the second policy goal ('A high proportion of those young adults who have left education having a job') it seems that the above logic was followed, in the sense that the reference category is here 'being unemployed or being out of the labour force'. However, in this case we propose to reformulate this policy goal to refer explicitly to aiming for low levels of unemployment, to make this goal more distinct from the first one. The term 'young adults' is used to refer to an older age category (in most cases the 20-24-year-olds, sometimes it will also include the 25-29-year-olds). However in this case we propose to include the youngest age group as well. We propose the following formulation: 'A low proportion of young people at any one time being unemployed'.

The third policy goal ('Few young people remaining unemployed for lengthy periods after leaving education') is an important addition to this, because the incidence of unemployment is different from the duration of the unemployment spells. Even if the overall unemployment rate is low, it may have a strong negative effect if the unem- 
ployment duration is very long. It is therefore important to add a policy goal that captures the importance of reducing the length of unemployment spells.

The last policy goal ('Stable and positive employment and educational histories in the years after leaving upper secondary education') is a bit ambiguous in its formulation. Questions to be raised are: What exactly is meant with a positive employment history or educational history? Why should this only refer to careers after leaving upper secondary education? Is it fruitful to merge employment histories and educational histories into one policy goal? Given these ambiguities, we propose to drop this policy goal and try to capture elements of it in new policy goals that are less ambiguous. With respect to the dimension of quantitative matching, we might be inclined to formulate a policy goal relating to stable employment histories as a desirable outcome. A stable employment history can be defined as having long employment spells and few disruptions of the occupational career with periods of unemployment. The latter aspect is already captured by the two former policy goals relating to the incidence and duration of unemployment spells. This policy goal should therefore focus on long employment spells. The problem here is that by definition the period of transition is characterised by a succession of employment spells. Jobseekers have incomplete information on the demand side of the labour market and - conversely - employers have incomplete information on the supply side. Both go through a necessary process of 'trial and error' before an optimal match is reached. Job hopping is therefore not necessarily a bad thing and can even be regarded an essential instrument to learn about the possibilities on the labour market and about one's own possibilities and preferences. One could even argue that having a maximum of stability (staying in one job during the whole career) is a sign of inflexibility rather than a desirable outcome. The problem is of course that having too many job spells is an undesirable outcome as well. However it is difficult to draw a good line and we therefore propose to refrain from formulating a policy goal in this area and to take the aspect of job security up as an indicator of the outcomes of the employment system.

It is surprising to note that no policy goals have yet been formulated with respect to the qualitative aspects of the matching process. This is not because qualitative mismatches have not been on the policy agenda's. On the contrary, one can note growing concerns since the late 80's about overqualification and underutilisation ${ }^{1}$. Qualitative mismatches are important because they can result in an underutilisation of the available stock of human capital. Working in a job below one's educational level poses a limitation on the utilisation of skills and a ceiling to the worker's productivity, resulting in lower wages (Cohn \& Khan, 1995). Moreover, mismatches have negative effects on labour turnover (Hersch, I99I) and job satisfaction (Tsang \& Levin, 1985). Given the importance of qualitative aspects of the matching process, we propose to add the following policy goal: 'A low proportion of young adults having work that

I. Similar concerns have been uttered from the employer's point of view relating to skills shortages. Given the focus of our framework on the perspective of the people making the transition (see footnote 2), we refrain here from formulating policy goals in this area. 
does not match their educational qualifications and/or in which they have insufficient opportunities to utilise their competences'.

The equity dimension is already covered by the earlier proposed policy goal.

\section{Outcomes of the employment system}

No policy goals have yet been formulated with respect to the quality of jobs. This is clearly an omission. If we are concerned about young people achieving high levels of educational attainment, we should equally be concerned about young people ending up in jobs that are of good quality and require a high level of skills.

One of the relevant aspects describing the quality of the jobs is the required educational level. Technological changes increase the skill demands in the labour market and it is generally assumed that a large proportion of the future jobs will require a tertiary level qualification (Tessaring \& Wannan, 2004). Moreover, high-level jobs offer better opportunities to develop one's skills and to contribute to innovations. At the other side of the skills spectrum, it is believed that jobs for which no or only a few years of education is required will offer no possibilities to develop one's skills. Other indicators of the quality of the jobs relate to wages of or job security (Van der Velden \& Wieling, 1994).

It is not easy to formulate policy goals that unambiguously point to desirable outcomes related to the quality of jobs. High wages for instance may be regarded as a desirable outcome at an individual level and is clearly an indicator of the quality of the jobs, but it does not in itself constitute a desirable outcome in policy terms (even if it does reflect high productivity levels). The same applies to other terms of employment, like having a permanent contract. Desirable as this may be at the individual level, having high proportions of young people working on a permanent contract may also reflect a high degree of labour market regulation and a lack of flexibility. We therefore propose to formulate this policy goal with respect to the quality of the jobs in more general terms: 'High proportions of young adults ending up in jobs that are of high quality, motivating and assuring independence'.

The adult learning and equity dimensions are already covered by the earlier proposed policy goals.

In sum, we propose the following policy goals for monitoring transition systems:

1. High proportions of young people completing a full upper secondary education with a recognised qualification for work, tertiary study or both;

2. High proportions of young adults completing a tertiary education;

3. High levels of competences among young people when they enter the labour market; 
4. A low proportion of young people being at the one time not in education and not at work;

5. A low proportion of young people at any one time being unemployed;

6. Few young people remaining unemployed for lengthy periods after leaving education;

7. A low proportion of young adults having work that does not match their educational qualifications and/or in which they have insufficient opportunities to utilise their competences;

8. High proportions of young adults ending up in jobs that are of high quality, motivating and assuring independence;

9. Good opportunities for young adults outside the education system to return to education to study towards a formal upper secondary education degree or higher;

10. High proportions of young adults outside the education system having good opportunities to develop their competences;

11. An equitable distribution of these outcomes for risk groups compared to nonrisk groups (e.g. by gender, social and ethnic background etc). 


\section{Empirical indicators for monitoring transition systems}

\subsection{Introduction}

After having formulated the theoretical framework, a major challenge is to formulate empirical indicators for each of the dimensions that are distinguished. Let's first elaborate what constitutes a good indicator. We have to realise that an indicator is not the same as a descriptive statistic. We may have good reasons to present descriptive statistics on the transition from school to work, but these do not necessarily constitute good indicators. Some differences are:

- Indicators should be clearly qualified as indicating something 'desirable' or something 'undesirable'. Descriptive statistics on the other hand 'only' need to paint a relevant aspect of the issues that are being studied.

- Indicators are typically used to monitor progress in a certain policy area. They constitute important instruments for policy makers to evaluate their policies. Descriptive statistics on the other hand serve a much broader goal. They may be used by anyone who has an interest in finding out particular aspects of a certain field of study.

- The number of indicators is preferably limited. The basic message to policy makers will not improve by an overload of indicators. For descriptive statistics on the other hand, there are only practical limitations, such as how many can be published in a book. ${ }^{\mathrm{I}}$

There are common elements as well. Both indicators and descriptive statistics need to be robust, based on reliable sources, and be published on a regular basis to allow time series.

Although our primary concern is to develop a set of indicators, we will also pay attention to the development of a limited set of descriptive statistics or descriptors as we shall call them. Indicators are always related to a policy goal and thus to monitoring outcomes of the three systems. Descriptors can sometimes be related to an outcome (when it does not reflect a policy goal), but most of them will be related to the structural and institutional factors that have been distinguished. We will restrict ourselves to those descriptors that we think are necessary for explaining outcomes in the three systems. This also means that indicators should be published on an annual basis in

I. Making statistical information available on the internet, preferably through interactive applications, greatly reduces such practical problems. 
Education at a Glance (EAG), while the descriptors will only be taken up in EAG when there is an interest in explaining country differences in these outcomes. We would like to propose however, that a special MTS publication will be made (comparable to the YALLE publication: OECD/CPRN, 2005) which tries to analyse transition systems using the full theoretical framework and related indicators and descriptors.

In the elaboration of indicators and descriptors, we adopted a pragmatic approach. First of all, the Thematic Review has already identified I4 different indicators that have been suggested as an indicator for the monitoring of transition systems (see section 2). These and related indicators are at present taken up in EAG or as part of the OECD transition data collection and will be reviewed for their relevance for the proposed framework. Second, the YALLE project (OECD/CPRN, 2005), which was carried out under the auspice of the Network, explored other indicators based on national labour force surveys. The findings of this project have also been taken into account. Third, we explored existing statistics from OECD (i.e. OECD Employment Outlook, OECD Economic Outlook and OECD Science, Technology and Industry Scoreboard) and EUROSTAT for relevant indicators. Fourth, we explored some international data sources for relevant questions that could be used as empirical indicators of one of the dimensions in the framework. We selected only data sources that are based on international comparative research and which cover a broad range of countries. Moreover, the surveys in question should be held on a regular basis so that it can play a role from a monitoring perspective. The following data sources have been explored (see appendix a for a description):

The European Social Survey (ESS: >20 countries)

- The European Community Household Panel (ECHP: Is countries);

- The International Social Survey Programme (ISSP: 40 countries);

- European Value Study (EVS: 33 countries);

- The International Adult Literacy Survey (IALS: 22 countries);

- The European Union Labour Force Survey (EULFS: is countries and comparable LFS in other countries);

In practice most of these data sources are too small to be of any practical use for our purpose. The ESS, ISSP, EVS and IALS are surveys covering some $1500-3000$ respondents per country. As these are usually comprised of the whole range of 15 -64-year-olds, the relevant group in these data sources, the $15-24$-year-olds, is much smaller. Based on estimates of the EULFS 2000 (EU-I5) the proportion of working 15-24-year-olds in the total population of $15-64$-year-olds is $9,2 \%$ (own calculation). This means that in these data sets, the relevant groups make up only a couple of hundred respondents in each country. We therefore restricted our proposal for new indicators to the EULFS and ECHP. From each of these two data sources we identified the questions that bear a possible relevance to the monitoring of transition systems. These questions are taken up in appendix b.

A data source that will not be explicitly discussed here is the EULFS Ad Hoc Module 2000. These data have been extensively analysed by Kogan \& Müller (2003). They 
show some advantages compared to the standard EULFS questions. However, given the lengthy time interval between the first module (2000) and the next one (2009), we propose to use this data source for a specific additional analysis on transition issues (like the YALLE publication), and to keep the focus here on finding indicators that can be updated on a more regular basis.

\subsection{Some definition issues}

Before we review each of these indicators in the light of the elaborated framework, we have to consider some definition issues.

\section{School-leaver cohorts or age cohorts?}

Up to now, the information on the transition from school to work in EAG is based on age groups instead of school-leaver cohorts. Although using age groups has a number of practical advantages, a major drawback is that lower educated are typically overrepresented in the data. However this does not necessarily mean that indicators based on age cohorts do not yield valuable information. From the perspective of monitoring transition systems, the main consideration would be if the rank order of countries would differ much if we used indicators based on school-leaver cohorts instead of age groups. Another alternative is to construct synthetic cohorts using typical graduation ages for given levels of education in different countries. ${ }^{2}$ We analysed the differences between age groups, entry cohorts based on typical graduation ages and entry cohorts based on actual age of leaving education, using data from the EU LFS 2000 ad hoc module on school-to-work transitions (see appendix c).

Our conclusion is that in general the differences between countries are quite small. Compared to the 'gold standard' of using real cohorts of school-leavers, analyses based on age groups give quite good results. For most of the indicators relating to employment chances or terms of employment, it is best to take the age group of 20-24-yearolds. It should be noted however that using the age group of 20-24-year-olds tends to underestimate the differences by educational level. More specifically the unemployment rates for the lower educated are underestimated in each country. The rank order of countries however does not change. For some of these indicators we will also calculate the same indicators for the 15-19-year-olds, as this group constitutes a particularly vulnerable group on the labour market. When analyses on occupations are concerned, it is best to take an older age group, namely the 25-29-year-olds. Finally, for the training variables it is best to take the 15-29-year-olds.

2. See Gangl (2003) for a further elaboration of this approach. 


\section{Definition of being in education or at work}

In EAG persons in education are defined as those attending part-time or full-time education, usually referring to the first quarter of the calendar year (thus excluding summer holiday employment). An alternative would be to define a person as being in education if he or she attended an education or training institution in the survey reference week or in the last four weeks prior to the survey. We suggest following the EAG definition.

Like in EAG we also propose that students in work-study programmes are considered to be both in education and employed irrespective of their labour market status according to the ILO definition during the survey reference week. The main argument here is that this is the proper way to reflect the double status (Wolbers, 2003) of these students. This means that they are counted as employed labour force in the relevant indicators.

A problematic category is the group working students (in EAG the category 'in education and other employed'). In EAG they are also counted as being in education as well as being part of the labour force. However, most of these students have side jobs, working a couple of hours per week in unskilled or semi-skilled jobs (e.g as waiter). The proportion of the category 'in education and other employed' in the total group of being in education is rather large, especially in the age groups 20-24 (over 25\%) and 25-29 (over 50\%). The question is whether we should take these people up in indicators referring to the labour force. We propose to exclude them because they paint a distorted picture of the youth labour market. However, it is an interesting category in its own regard and should be kept as a separate category of the group 'in education'.

The same holds for the category 'in education and unemployed'. This category probably comprises some 'discouraged workers', young adults who couldn't find a job and therefore continued to stay in education. On the one hand one could argue that they should be counted as unemployed, because not counting these people would give an underestimation of the 'real' unemployment rate. On the other hand, we should treat all people in the labour force in the same way. If we decide not to count working students as being part of the labour force, we should also exclude the unemployed students. Given the fact that the percentages involved are quite small (between $0,6 \%$ and $\mathrm{I}, 7 \%$ of the respective age group), we propose to exclude these people when calculating the unemployment rates.

\section{Different youth groups}

As outlined earlier, we can distinguish different groups. We will use the term 'teen-

3. For the indicators relating to unemployment rates we propose to calculate both the 'official' unemployment rate (including the working students) and the non-students unemployment rate to see whether these yield any differences. 
agers' to refer to the 15-19-year-olds. The term 'young adults' is used to refer to an older age category (in most cases the 20-24-year-olds, sometimes it will also include the 25-29-year-olds). The term 'young people' will be used to refer to the group of I5-24-year-olds.

\subsection{Empirical indicators for each dimension}

\subsubsection{Indicators for the education system}

Quality of the output

Below we recapitulate the original formulated indicators with respect to this dimension (between brackets relevant table in EAG 2005):

- Per cent not in education one year after the end of compulsory schooling. This indicator is at this moment not directly available, but could be derived from combining the information in EAG: CI. 4 Transition characteristics at age $15,16,17,18,19,20$ ) with information on the country-specific ending age of compulsory education (EAG: Cr.2). Nevertheless this indicator does not seem a very solid one to measure the related policy goal (High proportions of young people completing a full upper secondary education with a recognised qualification for work, tertiary study or both).

- Per cent of 20-24-year-olds whose highest level of education is lower secondary school. A problem with this indicator is that people might still be following education and obtain an upper secondary education degree. A better alternative is the presently used ' $\%$ of 20-24-year-olds who are not in education and have not attained upper secondary education (EAG: C5.I). Although in this case, people might still return to education and obtain an upper secondary education degree later in life, it is clear that this group is more at risk of not getting a qualification that is recognised as a minimum to pursue their study in tertiary education or to start working.

- Apparent upper secondary graduation rates (EAG: chart A2.I). This indicator is based on counts of first-time graduates in upper secondary education regardless of age per Ioo people at the typical graduation age. Given the fact that cohort data are lacking (which would have been the best way to calculate graduation rates) it is the best indicator for the related policy goal ((High proportions of young people completing a full upper secondary education with a recognised qualification for either work, tertiary study or both). The only problem is that this indicator cannot be distinguished by social group and is missing for a number of countries. We also compared this indicator with the former one (see appendix e). Our conclusion is that both indicators give complementary information and it is useful to consider both.

- Per cent of 25-29-year-olds with tertiary qualifications. A problem with this indicator is that average graduation ages vary considerably between countries 
and in many countries the average is well above 25 . An alternative is to use an older age group, namely the 30-34-year-olds, but the drawback is that this would relate to a different age group than the other indicators. We therefore propose to use the original indicator, but to include the 25-29-year-olds who are still in tertiary education (assuming that they will receive a diploma). The present alternative in EAG is to use apparent Tertiary-type A graduation rates. Like the apparent upper secondary graduation rates, this indicator is based on counts of first-time graduates in Tertiary-type A programs regardless of age per Ioo people at the typical graduation age (EAG: A3.I). Although in principle this indicator is the best proxy for the related policy goal (High proportions of young people completing a tertiary education), it has two drawbacks. First, this indicator cannot be distinguished by social group and is missing for a number of countries. Second, the indicator may give an overestimation of the policy goal for those countries that are net importers of tertiary education graduates and vice versa. We also compared this indicator with the ' $\%$ of $25-34$ year-olds with tertiary qualifications', see appendix e. Again we concluded that both indicators give complementary information and it is best to use both.

- Per cent of I6-25-year-olds at document literacy level $4 / 5$. This indicator was based on the IALS study carried out between 1994 and I998. Currently new information on prose, document and numerical literacy is available from the ALL study carried out between 2002 and 2006. A new wave is planned for 2009 (PIAAC). An alternative source is the PISA study that offers information on the skill levels of 15 -year-olds for reading, mathematics and problem solving (EAG 2004: A6.I; EAG 2005: A4.I, A5.I). Some members of the Network have expressed their doubts of using PISA results to indicate skill levels of youth when entering the labour market. The main problem is that the skills at the age of 15 are not telling the same story as the skills at the moment of transition as was indicated in the policy goal (High levels of competences among young people when they enter the labour market). Following further education will probably increase the skill levels, so that at the moment of entering the labour market the skills will be higher than at the age of I5. Although IALS and its successors are arguably better indicators for our policy goal, a practical problem is that the time frame between the subsequent waves is very large (7-8 years) from a monitoring point of view and the relevant age group in these surveys is quite small. In practice it may therefore be helpful to use both sources of information to indicate the skill levels. Further analysis comparing the results of ALL and PISA will have to show whether the two sets of indicators lead to a similar ranking of countries. If they come up with pretty much the same results, the PISA study could be used as an alternative data source for the period between ALL and PIAAC. For the moment we assume that they will give comparable results and we will elaborate indicators for the PISA study (to be changed for ALL once the results of that survey are available). We propose to use both average scores in the three PISA domains as well as the percentage scoring below a certain level. The latter is important because a 
minimum level of skills is considered key for entering the labour market and countries show large variations in the percentage of young people reaching this minimum level.

Summing up, we propose the following indicators for the quality of the output of the educational system (I refers to Indicator and the number refers to the policy goal in question; in the case of multiple indicators for one goal an additional number is added):

1. Per cent of 20-24-year-olds who are not in education and have not attained upper secondary education (Ir.I);

2. Apparent upper secondary graduation rates (II.2);

3. $\%$ of 25-29-year-olds who either have a tertiary education qualification or are currently enrolled in a tertiary education programme (I2.I);

4. Apparent Tertiary-type A graduation rates (I2.2);

5. Average mathematics proficiency of 15 -year-olds (I3.I);

6. \% of 15 -year-olds at mathematics proficiency level 2 or below $\left(\mathrm{I}_{3.2}\right)$;

7. Average problem solving proficiency of 15 -year-olds (I3.3);

8. \% of 15 -year-olds at problem solving proficiency level 2 or below (I3.4);

9. Average reading proficiency of 15 -year-olds (I3.5);

$10 . \%$ of 15 -year-olds at reading proficiency level 2 or below (I3.6);

\section{Adult learning}

Educational systems differ in the opportunities they offer to return to education at later points in the career. EAG currently presents a descriptor that captures the extent to which the educational system provides adult learning, namely the extent to which older age groups are still participating in education (EAG: table CI.2). Apart from that, the Labour Force Surveys give an opportunity (not for all countries) to give an estimate of the number of low-qualified people who were at one time out of education, and have now returned to education to take up a full upper secondary education degree or above.

11. Students aged 30-44 as a percentage of the population of 30-44-year-olds (I9.I);

12. Students aged 45-59 as a percentage of the population of 45-59-year-olds (I9.2);

13. \% of I5-40-year-olds that are presently following education at ISCED level 3 or above and who were not in education one year ago and whose highest completed level of education is no more than ISCED 2 (I9.3);

\section{Equity with respect to outcomes of educational system}

Most indicators in EAG are already presented by gender and there seems no reason why we should not distinguish most of the above indicators by gender. This is possible 
for all indicators except indicators 2 and 4 . Doing this gives the opportunity to look at the absolute as well as the relative differences between the two groups. At this stage we do not propose to reduce the number of indicators for this equity dimension yet. Further analysis however may show that some differences are more relevant than others and that a number of indicators yield pretty much the same results. In that case the number of indicators may be further reduced. In any case the information in EAG concerning differences by gender is now presented at different places. This makes it not always easy to get a good picture of the gender gap. It might be worthwhile to put this information together in one table.

\section{Indicators I, 3, 5, 7, 9 by gender (III.I-5);}

Other distinctions to relevant equity groups (such as social and ethnic background) are currently missing. However, this information is to some extent available both in PISA and in most labour force surveys, as was shown in the YALLE publication. The YALLE publication used parent's education as an indicator of social background. In the national labour force surveys (mostly household surveys) this information about the parents is only available for those young adults still living with their parents. A problem is that this is a selective sub sample of the total group of young adults and therefore the results cannot simply be generalised to the whole population. The problem differs between age groups as well as between countries (OECD/CPRN, 2005: table C2.6). In the age group I5-19-year-olds more than $90 \%$ of the young people are still living with their parents. For the age group of 20-24-year-olds these figures range from $58 \%$ for the US and Canada to $92 \%$ for Italy. For this reason, we propose to use this variable only for indicators relating to the youngest age group. For convenience, we propose to differentiate two groups (young people whose parents have not attained upper secondary education and young people of whom at least one of the parents achieved upper secondary education or above).

15. Indicators 5, 7, 9 by social background (III.6-8);

The YALLE publication used country of birth to indicate migrant status distinguishing between young adults born in the country of residence and young adults born in another country. Again, we propose to follow the same logic as for the gender variable.

16. Indicators I, 3 5, 7, 9 by migrant status (III.9-I3);

\section{Factors with respect to the educational system}

As outlined earlier we have not formulated any policy goals related to the institutional or structural factors of the different systems. This means that we will also refrain from formulating indicators. However we will try to find empirical descriptors for each of the distinguished dimensions. These may be based on quantitative data or they can 
be more qualitative in nature. If data are not presently available, we will propose a strategy to gather information regarding these aspects.

With respect to the specificity of skills, the programme orientation gives a good indication. This information is at present only available for secondary education programmes (EAG: C2.I). For tertiary education it is more difficult to draw a sharp line between more general and more specific programmes, partly because of country-specific differences in the tertiary educational structure (e.g unitary vs. binary systems; one- or two-tier systems, existence of Type B programmes), partly because the distinction between general and specific programmes does not simply coincide with a distinction between types of programmes like university and non-university tertiary programmes. We therefore propose to use only one descriptor for this dimension (descriptors will be denoted with the letter $\mathrm{D})$.

17. \% of students enrolled in vocational programmes in upper secondary education (DI);

The second factor that was distinguished in the theoretical framework was responsiveness or the sensitivity of the educational system to changes in the requirements in the employment system. This is typically a factor where systematic information is lacking, although there is a broad consensus that this is very relevant for improving the schoolto-work transitions. The main reason for this is that it is difficult to measure anything related to this in the usual surveys. That does not mean that no systematic information can be gathered. We propose that the Network B will start to collect some qualitative data with respect to this dimension, pretty much in a similar way as has been done in the Employment Outlook with respect to employment protection legislation. Relevant questions are for example: are employers systematically involved in the design and evaluation of curricula? Does 'labour market relevance' play a role in the accreditation and quality assurance of study programmes? How often are programs evaluated? These qualitative data can in later phase be used to construct an index for responsiveness.

18. Index for responsiveness of the educational system (D2, to be developed);

Much of what has been said with respect to responsiveness also applies to the reliability of the educational credentials. Many scholars in comparative research assert that this is one of the most important features of the educational system, yet systematic information is lacking. Hannan et al. (1996) and Shavit \& Müller (1998) present classifications of countries based on the stratification and standardisation of the educational system. Some of this information is also available in the EAG, Table D6.I, Structural features of school systems across the OECD countries. A good indicator is the age at which differentiation takes place. We propose to use the information from all three sources to construct an overall index of reliability of the educational credentials. 
19. Index of reliability of the educational credentials ( $D_{3}$, to be developed);

\subsubsection{Indicators for the transition system}

\section{Quantitative matching}

Not surprisingly many of the existing indicators and descriptors refer to this dimension. The Thematic Review identified no less than 7 indicators in this area. Let's review each of these indicators.

- Non-student unemployed as a per cent of all I5-I9-year-olds (EAG C4.2). This indicator is a direct reflection of policy goal 4 in its original formulation. However, as we outlined in section 4 , we propose to change this policy goal into 'a low proportion of young people being at the one time not in education and not at work'. This is indicated by the present indicator: \% of 15-19-yearolds who are neither in education nor at work (EAG: Chart C5.2). Given the fact that we extended the relevant age group, a similar indicator should be calculated for the 20-24-year-olds.

- Unemployment to population ratio, I5-I9-year-olds (approximation in EAG C4.3: \% of the population not in education and unemployed in the total population by level of education attained, age group and gender). This indicator is related to policy goal 5 . The problem is that it does not really reflect the unemployment chances, as the ratio will be highly affected by the proportion of people still in education. On the other hand, unemployment in the total population is also a relevant indicator. We therefore propose to supplement this indicator with the unemployment rate of I5-I9-year-olds. This unemployment rate can be calculated in the usual 'official' way, which would include working and unemployed students as being in the labour force or we can exclude the students. For the time being, we propose to use both definitions and analyse to what extent they yield different results.

- Unemployment to population ratio, 20-24-year-olds (approximation in EAG C4.3: \% of the population not in education and unemployed in the total population by level of education attained, age group and gender). For this indicator we propose the same change as for the former one.

- Per cent of non-students employed, age 20-24 (at this moment not directly available; to be derived from EAG $\mathrm{C}_{4.2 \mathrm{a}} \%$ of the youth population in education and not in education by age group and work status: \% employed in total group not in education). This indicator is a direct reflection of policy goal 5 in its original formulation. However, as we outlined in section 4, we propose to change this policy goal into 'a low proportion of young people at any one time being unemployed'. This is already captured by the former two indicators.

- Employment to population ratio, 20-24-year-olds (at this moment not directly available; to be derived from EAG $\mathrm{C}_{4.2 \mathrm{2}} \%$ of the youth population in education and not in education by age group and work status: sum of $\%$ employed 
in education and \% employed not in education). This indicator suffers from the same problem as was outlined for the two indicators relating unemployment to population ratio's. The reference category here is very heterogeneous (it comprises the unemployed as well as those in education) and does therefore not necessarily point to a desirable outcome.

- Per cent of unemployed I5-I9-year-olds unemployed for six months or more (available but not published in EAG). This indicator adds valuable additional information as long unemployment spells are known to have lasting effects on the occupational careers (Van der Linden \& Van der Velden, 1998). This indicator can be regarded as a good indicator of policy goal 6 .

- Per cent of unemployed 20-24-year-olds unemployed for six months or more (available but not published in EAG). For the same reason as above, we propose to add this indicator.

All other statistics in EAG relating to these issues (e.g. 'Expected years in education and not in education by work status for 15-29-year-olds' (EAG: C4.Ia) or '\% of the youth population in education and not in education by age group and work status' $\left(\mathrm{C}_{4}\right.$.2a) $)$ can be regarded as descriptors. They are highly informative, but cannot directly be used as an indicator.

In our search for alternative indicators, we found one other indicator relating to unemployment. In some cases the distinction between being employed or being unemployed is too crude. Some people may actually have a part-time job (which would count them in the statistics as being employed), while they actually would like to have a fulltime job. This can be considered a case of underemployment. We therefore propose to add an indicator reflecting this issue: \% of workers, 20-24-year-olds, working involuntary part-time.

Summing up we propose the following indicators for the dimension of quantitative matching:

20. \% of I5-I9-year-olds who are neither in education nor at work (I4.I);

$21 . \%$ of $20-24$-year-olds who are neither in education nor at work ( $\left.\mathrm{I}_{4} .2\right)$;

22. Unemployment rate I5-I9-year-olds (I5.Ia);

23. Non-student unemployment rate I5-I9-year-olds (I5.Ib);

24. Unemployment to population ratio I5-I9-year-olds (I5.Ic);

25. Unemployment rate 20-24-year-olds (I5.2a);

26. Non-student unemployment rate 20-24-year-olds (I5.2b);

27. Unemployment to population ratio 20-24-year-olds (I5.2c);

28. \% of workers, 20-24-year-olds working involuntary part-time (I5.3);

29 . \% of unemployed I5-I9-year-olds unemployed for six months or more (I6.I);

30 . \% of unemployed 20-24-year-olds unemployed for six months or more (I6.2); 


\section{Qualitative matching}

No indicators have yet been formulated with respect to this dimension. However combining information about the educational background and the occupation in which young adults are working does give some rough indication about level mismatches. The International Standard Classification of Occupations (ISCO88) distinguishes 8 major groups at 4 different skill levels and 2 major groups without an explicit reference to a required skill level. The skill levels are defined in the (old) ISCED classification of 1976: level I primary education (ISCED I), level 2 secondary education (ISCED 2 and 3), level 3 tertiary non-university education (ISCED 5 ) and level 4 tertiary university education (ISCED 6 and 7). Unfortunately the classification does not distinguish properly between lower and upper secondary education. Therefore it is not possible to distinguish the people with a recognised qualification for work (full upper secondary education) from those who lack such a certificate. Moreover the present ISCED $5 \mathrm{~A}$ category comprises both non-university degrees (e.g. Fachhochschule, $\mathrm{HBO}, \mathrm{AMK}$ ) and university degrees. This means that we can distinguish only people with a tertiary education degree working at skill level I or 2 and people with a secondary education degree working at skill level I as being overqualified. As indicated earlier, indicators that relate to the content of the job are best measured for the age group 25-29-year-olds.

Apart from this it is important to find indicators relating to the utilisation of skills. This information is not standard available in the Labour Force Surveys, but it is a more or less standard question in many school-leaver surveys. Fortunately, this information is also available in the European Community Household Panel (ECHP: qI4). This survey also gives information on another important aspect, namely the job satisfaction (ECHP: q30). Although high levels of job satisfaction are not formulated as a policy goal, it does give a good idea of the extent to which expectations of the job seeker have been realised and can thus serve as a descriptor of the indicator of the matching process.

31. \% of workers, 25-29-year-olds with a tertiary education degree, working at skill levels I or 2 (ISCO groups 4-9) (I7.I);

32 . $\%$ of workers, 25-29-year-olds with a secondary education degree, working at skill level I (ISCO group 9) (I7.2);

33. \% of workers, 25-29-year-olds, indicating that they have the skills or qualifications to do a more demanding job than they currently have (I7.3);

$34 . \%$ of workers, 25-29-year-olds, indicating that they are satisfied with their current job (I7.4);

\section{Equity related to the transition system}

Following the same logic as outlined in the case of the outcomes of the education system, we can elaborate some equity indicators for the outcomes of the transition 
system as well. As outlined earlier, we can only calculate differences by social background for the I5-I9-year-olds.

35. Indicators of quantitative matching for I5-19-year-olds (indicators 20, 22-24, 29) by gender (III.I4-I8);

36. Indicators of quantitative matching for 20-24-year-olds (indicators 2I, 25-28, 30) by gender (III.I9-24);

37. Indicators of qualitative matching for 20-24-year-olds (indicators 3I-34) by gender (III.25-28);

38. Indicators of quantitative matching for I5-I9-year-olds (indicators 20, 22-24, 29) by social background (III.29-33);

39. Indicators of quantitative matching for I5-19-year-olds (indicators 20, 22-24, 29) by migrant status (III.34-38);

40. Indicators of quantitative matching for 20-24-year-olds (indicators 2I, 25-28, 30) by migrant status (III.39-44);

41. Indicators of qualitative matching for 20-24-year-olds (indicators 3I-34) by migrant status (III.45-48);

The YALLE publication demonstrated clearly the significance of educational background in labour market outcomes, especially in distinguishing those lacking a certificate of upper secondary education, versus those with a certificate of upper secondary education or above. A possible problem is that level of educational attainment and labour market experience is strongly correlated with age. In OECD/CPRN (2005), the YALLE group (20-24-year-olds without upper secondary level of education) was therefore systematically compared with 5 different subgroups by age and level of education. Although this approach does justice to the problem of trying to compare relatively incomparable groups, it also introduces a problem of giving a lot of information. This problem would not have occurred if school-leaver cohorts were used instead of age groups. The question is comparable to the one raised earlier: is it harmful to use age groups instead of school-leaver cohorts when comparing lower educated versus higher educated (upper secondary education or above)? Again we used the data from the EULFS ad hoc module to compare the results using the age group approach and using the cohort approach. Appendix d presents the results. In line with the expectations, the age group approach reports somewhat lower unemployment rates for the lower educated group than the cohort approach. Nevertheless, the differences in unemployment rates between the two methods are quite small, and the differences between the countries is not seriously affected ( $\mathrm{r}=0.97$ for the ISCED 0-2 group and $r=0.99$ for the ISCED 3-6 group). Also the ratio's of the unemployment rates by educational level correlate quite high between the two methods $(r=0.84)$.

We conclude that with respect to the dimension of quantitative matching, there is little harm in comparing 20-24-year-olds with a low level of education with those young people having upper secondary education degrees or above. A problem may arise when calculating the indicators related to the chances of working in a job for 
which one is overqualified, because by definition the lower educated group is not formally overqualified for any job. However, they can end up in jobs in which their skills are not sufficiently used. We therefore propose to add the following indicators with respect to the equity dimension:

42. Indicators of quantitative matching for 20-24-year-olds (indicators 2I, 25-28, 30) by level of education (IrI.49-54);

43. \% of workers, 25-29-year-olds, indicating that they have the skills or qualifications to do a more demanding job than they currently have by level of education (III.55);

\section{Factors related to the transition system}

Just like the case of the institutional and structural factors for the transition system we have tried to find empirical descriptors for each of the distinguished dimensions. If data are not presently available, we will propose a strategy to gather information regarding these aspects.

The first factor relates to the institutional linkages between the educational system and the employment system and the flexibility of pathways. One way of introducing strong pathways between the education system and the employment system is by designing programs that offer a strong link between school and work, like the dual system or other school-work based programs. This can easily be captured by the proportion of young people enrolled in school-work based programs (already available in EAG: C2.I). Another important way of providing opportunities to combine workplace experience with education is by offering work placements. Unfortunately this information is not available in the data sources that we have explored. Schoolleaver surveys very often provide this kind of information, but are only available for those countries that carry out such destination surveys. An alternative might be to look at public information regarding the study programs and to which extent work placement is a mandatory part of the program. A relevant descriptor could be: $\%$ of students enrolled in upper secondary and tertiary education programmes that include a mandatory work placement of at least 3 months. This information could be gathered through the members of the network. Finally, the percentage of students combining study with work experience is also an indicator of the divide between the world of education and the work and is already available (EAG: $\mathrm{C}_{4} \cdot 3$ ). In sum we propose the following descriptors:

44. \% of students enrolled in school-work based programmes in upper secondary education (D4);

$45 . \%$ of students enrolled in upper secondary and tertiary education programmes that include a mandatory work placement of at least 3 months ( $\mathrm{D}_{5}$, to be developed); 
46. \% of students enrolled in upper secondary and tertiary education programmes I5-24-year-old that are working (D6);

The second factor concerning transparency relates to the existence of good information and guidance practices. In the data sources that we explored no information relating to this issue has been found. School-leaver surveys often contain this kind of information, for example questions on occupational counselling practices at school. This information could be used to formulate a descriptor like: ' $\%$ of school-leavers that was engaged in occupational counselling at the former school' or ' $\%$ of schoolleavers that is satisfied with the occupational counselling at the former school'. As an alternative, more qualitative information could be gathered by the Network members about information and guidance practices in their country. Apart from providing examples of good practice, this kind of information could be used to construct an overall index regarding information and guidance practices.

47. Index on information and guidance practices ( $\mathrm{D}_{7}$, to be developed);

The third factor related to the support structure of the transition system. One important source of information is the public spending on Active Labour Market Programs for youth as a percentage of GDP. These are regularly published in the OECD Employment Outlook. Also available is information from the EULFS on the number of people that received support from the public employment office in finding the present job.

48. Public spending on Active Labour Market Programs for youth as a percentage of GDP (D8);

49. $\%$ of workers, 20-24-year-olds, that received support from the public employment office in finding the present job (D9);

The openness of the transition system can be indicated by the extent to which new entrants in the labour market have the same opportunities to get a job as those who are already in the employment system. Relative unemployment rates for different age groups paint a good picture of this aspect of openness. The proportion of first job seekers among the unemployed (available in YALLE) is an alternative indicator. Another aspect of openness, already indicated in the theoretical framework, relates to the ease with which people can start their own business. Self-employment can be an important alternative for salaried work and countries may differ significantly in the opportunities they offer for young adults to start their own business. As school-leavers usually do not start self-employment immediately after leaving school, it is best to take an older age group for this indicator.

50. Ratio of the unemployment rate among 20-24-year-olds to the unemployment rate among 25-64-year-olds (Dio);

51. Proportion of first job seekers among the unemployed (DiI); 
52. \% of workers 25-29-year-olds that is self-employed (Di2);

\subsubsection{Indicators for the employment system}

\section{Quality of the output}

The following policy goal has been formulated with respect to this dimension: 'High proportions of young adults ending up in jobs that are of high quality, motivating and assuring independence'.

One important quality aspect concerns the level of the occupation young people end up in. As indicated earlier, the ISCO classification distinguishes Io major groups, 8 of which were assigned a specific skill level. We use these to derive our indicators. Bearing in mind the results in appendix c, we propose to use here the group of 25-29year-olds.

53. \% of workers, 25-29-year-olds, working as 'Technicians and associate professionals' (ISCO major group 3) or as 'Professional' (ISCO Major group 2) (I8.I);

54. \% of workers, 25-29-year-olds, working in 'elementary occupations' (ISCO Major group 8) (I8.2);

Apart from these indicators, we propose to add some other aspects to describe the quality of the jobs: earnings (based on LFS data or ECHP), working fulltime (EULFS), working in a permanent job (EULFS) and looking for another job because of risk of loosing present job (EULFS). These can be regarded as relevant aspects of the quality of a job

55. Median earnings from employment for 20-29-year-olds converted in US dollars using PPP (I8.3);

$56 . \%$ of workers, 20-24-year-olds, working fulltime (I8.4);

$57 . \%$ of workers, 20-24-year-olds, working in a permanent job (I8.5);

58 . \% of workers, 20-24-year-olds, looking for another job because of risk of loosing present job (I8.6);

\section{Adult learning}

With respect to the learning possibilities in the employment system, the EULFS provides information on the training received in the four weeks before the survey as well as the nature of this training (job related/ professional or other). More specific information will become available in the specific surveys on adult learning. For the moment however we suggest to use the current information from the EULFS. 
Bearing in mind the results of appendix c, we propose to use the age group of $15-29-$ year-olds.

59. \% of workers, 15-29-year-olds, participating in job related or professional training in previous 4 weeks (Iro);

\section{Equity with respect to outcomes of the employment system}

Again we will develop indicators for the differences between the relevant equity groups. As indicated earlier, a distinction by social background is not possible here as all indicators and descriptors refer to age 20 and above. Moreover for the indicators on level of occupation ( 53 and 54) it does not make much sense to make a distinction by level of education. This means that we end up with a total of 19 equity indicators.

60. Indicators 53-59 by gender (III.56-62);

61. Indicators 53-59 by migrant status (III.63-69);

62. Indicators $55-59$ by level of education (III.70-74);

Factors with respect to the employment system

The OECD Employment Outlook provides information on the extent of regulation. Labour market regulation is indicated by variables like the collective bargaining structure, collective bargaining coverage, trade union density and employment protection legislation. We propose to use only the latter as a descriptor for the extent of regulation.

63. Index of employment protection regulation (Di3);

\subsubsection{Indicators for the contextual factors}

\section{Economic conditions}

As indicated in the Thematic Review 'a well functioning economy is perhaps the most fundamental factor to shape young people's transition from initial education to work' (OECD, 2000: 13). Young people's chances to find a job are primarily determined by the general labour market conditions (Van der Velden \& Wolbers, 2003). Moreover, new entrants to the labour market are more affected by ups and downs in the business cycle than the existing labour force. Information concerning the economic conditions can be taken from OECD Economic Outlook (Annex Table I and I4). We propose the following indicators:

64. Standardized Unemployment rate SUR (Di4); 
65. Relative change in total employment: total employment at year t divided by total employment at year t-I (Dis);

66. Growth rate of real GDP (Di6);

\section{Technology}

Developments in technology have a strong effect on the demand for skilled labour and the level of skills that is required. The OECD Science, Technology and Industry Scoreboard provides regular updates on a range of indicators, such as expenditure on R\&D as share of GDP, patent intensity, number of scientific articles etc. We propose the following descriptor for this dimension:

67. Expenditure on R\&D as share of GDP (Di7);

\section{Demography}

Demographic developments have major impacts on the job chances of young people in the labour market. Two types of indicators seem relevant here: relative youth cohort size and the relative size of those people in the labour force that are about to retire. Given the fact that new entrants in the labour market primarily compete with each other instead of with existing personnel, the first indicator determines the number of competitors that young people will meet when they enter the labour market. The second type of indicator determines the outflow of the employment system and thus the replacement demand on the labour market.

68. Share of 15 -24-year-olds in the population of 15 -64-year-olds (Di8);

69. Trend in share of 15 -24-year-olds in the population of 15 -64-year-olds (Di9);

70. Share of 55-64-year-olds in the population of I5-64-year-olds (D20);

71. Trend in share of 55-64-year-olds in the population of 15-64-year-olds (D2I). 


\section{Evaluation and further strategy}

In this section we will briefly summarise and evaluate the framework and related goals and indicators that have been developed in the previous sections. Then we will suggest some further strategy concerning the future analysis and monitoring of transition systems.

In the theoretical framework we distinguished several outcomes of the transition system as well as relevant structural and institutional factors that affect these outcomes. We argued that it is relevant to look at outcomes of the education system and the employment system as well as these determine supply and demand in the transition system. Moreover, we distinguished some relevant institutional factors in these systems as well. Finally we distinguished some relevant contextual factors that affect outcomes in all three systems.

We have used this framework as well as the results of the quick scan among Network $\mathrm{B}$ members, to evaluate the policy goals that were formulated in the Thematic Review (OECD, 2000). Important in this respect is that we suggested to formulate only policy goals with respect to the outcomes of the three systems and not with respect to structural and institutional factors that affect these outcomes. The following policy goals were suggested:

1. High proportions of young people completing a full upper secondary education with a recognised qualification for work, tertiary study or both;

2. High proportions of young adults completing a tertiary education;

3. High levels of competences among young people when they enter the labour market;

4. A low proportion of young people being at the one time not in education and not at work;

5. A low proportion of young people at any one time being unemployed;

6. Few young people remaining unemployed for lengthy periods after leaving education;

7. A low proportion of young adults having work that does not match their educational qualifications and/or in which they have insufficient opportunities to utilise their competences; 
8. High proportions of young adults ending up in jobs that are of high quality, motivating and assuring independence;

9. Good opportunities for young adults outside the education system to return to education to study towards a formal upper secondary education degree or higher;

10. High proportions of young adults outside the education system having good opportunities to develop their competences;

11. An equitable distribution of these outcomes for risk groups compared to nonrisk groups (e.g. by gender, social and ethnic background etc).

The next step was to try and formulate indicators that could be used to monitor these policy goals and to find descriptors that could be used for describing the relevant factor affecting the outcomes. Table 6.I provides an overview of these indicators and descriptors, mapped to the various aspects and policy goals.

\section{Table 6.1}

The relationship between the different dimensions of the theoretical framework on the one hand and transition policy goals and indicators on the other hand

\begin{tabular}{|c|c|c|c|}
\hline Dimension & Goals & Indicators & Descriptors \\
\hline \multicolumn{4}{|l|}{ Education system } \\
\hline Quality of output & $1-3$ & $1-10$ & \\
\hline Adult learning & 9 & $11-13$ & \\
\hline Equity & 11 & $14-16$ & \\
\hline Specificity of skills & & & 17 \\
\hline Responsiveness & & & $18^{*}$ \\
\hline Reliability & & & $19^{*}$ \\
\hline \multicolumn{4}{|l|}{ Transition system } \\
\hline Quantitative matching & $4-6$ & $20-30$ & \\
\hline Qualitative matching & 7 & $31-34$ & \\
\hline Equity & 11 & $35-43$ & \\
\hline Institutional linkages & & & $44,45^{*}, 46$ \\
\hline Transparency & & & $47^{*}$ \\
\hline Support structure & & & 48,49 \\
\hline Openness & & & $50-52$ \\
\hline \multicolumn{4}{|l|}{ Employment system } \\
\hline Quality of jobs & 8 & $53-58$ & \\
\hline Adult learning & 10 & 59 & \\
\hline Equity & 11 & $60-62$ & \\
\hline Regulation & & & 63 \\
\hline \multicolumn{4}{|l|}{ Contextual factors } \\
\hline Economic conditions & & & $64-66$ \\
\hline Technology & & & 67 \\
\hline Demography & & & $68-71$ \\
\hline
\end{tabular}

* indicates descriptors that need to be developed

Although the impression may have arisen that a massive number of indicators has been developed, the hard core of the system consists of only 35 indicators measuring the 
extent to which ro out of II policy goals have been reached. This is an average of three to four indicators per goal. For the eleventh goal (related to equity) the number of indicators is necessarily much larger. This has to do with the fact that for all outcomes (i.e. the other Io goals) indicators have to be developed that measure differences by gender, by social and ethnic background and by level of education.

Apart from the indicators, we have distinguished 2I descriptors. As outlined before we do not propose to make this part of the annual data collection for EAG. Rather they serve as relevant background material for analysing cross-country differences in the outcomes of the transition system. They could be part of a special publication on the transition from school to work or some of them could be taken up in EAG when a specific analysis on the relation between these factors and the outcomes will be made.

We would like to make the following recommendations for publication of the indicators and descriptors:

1. For all the indicators we propose to have an annual or at least a regular update so that progress with respect to reaching the policy goals can be closely monitored. This update should be made available as of EAG 2007. The hard core of 35 indicators should be published in the report, while for the equity dimension a selection of indicators can be chosen. The rest of the equity indictors should be made available on the web site.

2. An essential element of monitoring is that it allows looking at changes over time. EAG does not yet contain graphs that allow getting a quick overview of the changes in the relevant indicators, although this information is available in the different publications of EAG. Rather than having to work through all the subsequent versions of EAG, we propose that for at least one indicator of each policy goal a graph will be presented showing the developments over time.

3. Information on differences between different social groups is currently presented at different places in EAG. This does not always make it easy to get a good overview on the equity issues. We propose to make a separate section in which all information regarding differences between relevant equity groups are put together.

4. Apart from the monitoring of indicators through EAG, we propose to make a separate publication under the auspice of the Network, using the developed framework to analyse how structural and institutional factors affect the integration process of young people into the labour market.

As indicated above, there are still relevant aspects of the framework for which no data are available. This relates specifically to the following aspects:

- Institutional linkages between school and work (more specifically the proportion of students having work placements as part of their curriculum);

- Transparency of the transition system (information and guidance practices); 
- Responsiveness of the educational system to changes in the employment system;

- Reliability of the educational credentials (extent to which quality of the outflow is assured and national standards are set for curricula and examinations).

It is important that the Network will engage in activities to develop indices for each of these aspects. For the first aspect, quantitative data are probably available. For the other aspects a qualitative data collection should be carried out. However, given the work programme of Network B and especially the work for PIAAC, we propose to postpone this activity to 2008 .

Furthermore, a clear omission of the current labour force surveys is the lack of information on educational attainment of the parents for those respondents who are no longer living at home. Including this type of information would greatly enhance the potentials of this important data base.

Finally, a number of countries carry out school-leaver surveys that provide an interesting additional data source for monitoring transition systems. Given the fact that these surveys have been specifically designed to monitor the transition from school to work, they have a number of advantages over the existing data sources, that help improve our understanding of the underlying processes governing the school-to-work transition. A major drawback however, is that results of these national school-leaver surveys are often incomparable as a result of differences in sample design, questionnaires etc. ${ }^{I}$ Network B typically constitutes a platform where this harmonisation should be discussed and could take a leading role in enhancing international standards in school-leavers surveys. However, given the work programme of Network B, we propose to postpone this activity to 2008 .

I. An exception are those surveys that have started from an international comparative perspective like the CHEERS survey (http://www.uni-kassel.de/wzi/tseregs.htm) and the REFLEX survey (http://www. reflexproject.org) 


\section{References}

Allmendinger, J. (1988), Career Mobility Dynamics. A Comparative Analysis of the United States, Norway and West Germany, Thesis, Cambridge Massachusetts: Harvard University.

Becker, G.S. (1964), Human Capital, New York: National Bureau of Economic Research.

Borghans, L., \& De Grip, A. (2000), Skills and Low Pay: Upgrading or Overeducation? In M. Gregory \& W. Salverda \& S. Bazen (Eds.), Labour Market Inequalities. Problems and Policies of Low-wage Employment in International Perspective (pp. 198-223), Oxford: Oxford University Press.

Caroli, E., \& Van Reenen, J. (2001). Skill Biased Organizational Change? Evidence from a Panel of British and French Establishments, Quarterly Journal of Economics, 116, 4, 14491492.

Cohn, E. \& S.P. Khan (1995), The wage effects of overschooling revisited, Labour Economics 2, pp. 67-76.

CLFDB (1994), Putting the pieces together: Towards a coherent transition system for Canada's labour force, Report of the Task Force on Transition into Employment of the Canadian Labour Force Development Board.

De Grip, A. \& Van Loo, J. (2002), The Economics of Skills Obsolescence: A review, In A. de Grip, J. van Loo \& K. Mayhew (Eds.), Understanding Skills Obsolescence, Research in Labor Economics, JAI.

Esping-Andersen, G. and M. Regini (eds.) (2000), Why Deregulate Labour Markets, Oxford: Oxford University Press.

Finegold, D. \& Soskice, D. (1988), The Failure of Training in Britain: Analysis and Prescription, Oxford Review of Economic Policy, 4/3, 21 - 53.

Gangl, M. (2003), Methodological appendix: Using the European labour force survey for transition research. In W. Müller \& M. Gangl (eds.), Transitions from education to work in Europe. The integration of youth into EU labour markets (pp. 306-314), Oxford: Oxford University Press.

Glebbeek, A.C. (1988), De arbeidsmarktpositie van opleidingen. Ontwikkeling en illustratie van een theoretisch model, Tijdschrift voor Arbeidsvraagstukken, 4, 3, 75-89.

Goldstein, H. (1995), Multilevel Statistical Models, $2^{\text {nd }}$ edn. London: Arnold.

Hannan, D., Raffe, D. \& Smyth, E. (1996), Cross-National Research on School to Work Transitions: An Analytic Framework, Paper presented at the 1996 Workshop of the Network Transitions in Youth, September, La Ciotat.

Hartog, J. \& J. Theeuwes (1993), Labour Market Contracts and Institutions. A Cross-National Comparison, Amsterdam: North-Holland.

Hersch, J. (1991), Education Match and Job Match, Review of Economics and Statistics, 73, 
$140-4$

Keep, E. \& Mayhew, K. (1998), Was Ratner Right?, Product Market and competitive Strategies and their Links with Skills and Knowledge', Employment Policy Institute Economic Report, 12/3.

Kerckhoff, A. (1995), Institutional arrangements and stratification processes in industrial societies, Annual Review of Sociology, 15, 323-347.

Lindbeck, A. \& D. Snower (1988), The Insider-Outsider Theory of Employment and Unemployment, Cambridge, Mass.: MIT Press.

Linden, A.S.R. van der \& Velden, R.K.W. van der (1998), The Effects of Unemployment and Mismatches on Future Job Match and Earnings, in: Th. Lange (ed.) Understanding the School-to-Work Transition: An International Perspective, Nova Science Publishers, Inc., Commack, New York, pp. 109-124.

Loo, J. van, Grip, A. de \& Steur, M. (2001), Skills Obsolescence: Causes and Cures, Research Memorandum, Maastricht: ROA.

Machin, S. \& Van Reenen, J. (1998), Technology and Changes in Skill Structure. Evidence from Seven OECD Countries, Quarterly Journal of Economics, 113, 245-279.

Macunovich, D. (1999), The Fortunes of One's Birth. Relative Cohort Size and the Youth Labor Market in the United States, Journal of Population Economics, 12, 215-272.

Marsden, D. (1990), Institutions and Labour Mobility: Occupational and Internal Labour Markets in Britain, France, Italy and West Germany, In: R. Brunetta \& C. Dell'Aringa (eds.), Labour Relations and Economic Performance, 414-438, Houndmills: Macmillan.

Müller, W. \& Gangl, M. (2003), Using LFS data for cross-national research: Promises, examples, and problems, Paper presented at International Workshop on Comparative Data on Education-to-Work Transitions, OECD, Paris, 21-23 June 2000.

OECD (2000), From initial education to working life. Making transitions work, Paris: Organisation for Economic Co-operation and Development.

OECD (2005a), Education at a Glance 2005, Paris: Organisation for Economic Co-operation and Development.

OECD (2005b), Employment Outlook 2005, Paris: Organisation for Economic Co-operation and Development.

OECD (2005c), Economic Outlook 2005, Paris: Organisation for Economic Co-operation and Development.

OECD (2005d), Science, Technology and Industry Scoreboard 2005: Towards a knowledge-based economy, Paris: Organisation for Economic Co-operation and Development.

OECD/CPRN (2005), From education to work. A difficult transition for young adults wilt low levels of education, Paris: Organisation for Economic Co-operation and Development.

Przeworski, A. and Teune, H. (1970), The logic of comparative social inquiry, New York: Wiley. Ryan, P. (2001), The School-to-Work Transition: A Cross-National Perspective, Journal of Economic Literature, 39, 34-92.

Rosenbaum, J.E. (1984), Career Mobility in a Corporate Hierarchy, Orlando: Academic Press.

Shavit, Y. \& W. Müller (1998), From School to Work. A Comparative Study of Educational Qualifications and Occupational Destinations, Oxford: Clarendon Press.

Snijders, T. \& Bosker, R. (1999), Multilevel Analysis: An Introduction to Basic and Advanced 
Multilevel Modelling, London: Sage Publications.

Spence, M. (1973), Job Market Signalling, Quarterly Journal of Economics, 87, 1, 355-374.

Tessaring, M. and Wannan, J. (2004), Vocational Education and Training - Key to the Future, Lisbon-Copenhagen-Maastricht: Mobilising for 2010, Cedefop synthesis of the Maastricht study, Luxembourg.

Thurow, L.C. (1975), Generating Inequality. Mechanisms of Distribution in the U.S. Economy, New York: Basic Books.

Tsang, M. and Levin, H. (1985), The Economics of Overeducation, Economics of Education Review, 4, 93-104.

Turner, R.H. (1960), Sponsored and contest mobility and the school system, American Sociological Review, 25, 855-867.

Velden, R.K.W. van der \& Wieling, M.H. (1994), De arbeidsmarktkansen per opleiding, in: H. Scholten \& S.C. de Groot, Arbeidsmarkt en Sociale Zekerheid, Beleid in Beweging, pp. 106-104.

Velden, R. van der \& Wolbers, M. (2003). The Integration of Young People into the Labour Market: The Role of Training Systems and Labour Market Regulation, In W. Müller \& M. Gangl (eds.), Transitions from Education to Work in Europe. The Integration of Youth into EU Labour Markets (pp. 186-211), Oxford: Oxford University Press. 



\section{Appendix A \\ Description of data sources}

European Social Survey 2004/5 (ESS)

Design: cross-section, face-to-face interviews

Sampling: random sample of individuals

Size: I, 500 respondents of 15 years and over per country

Coverage: $>20$ countries

Topics: social values, cultural norms and behaviour patterns

Accessibility: http://ess.nsd.uib.no

Information: http://www.europeansocialsurvey.com

European Community Household Panel 1994-20oI (ECHP)

Design: panel, standardized questionnaires

Sampling: representative panel of households

Size: 60,500 household and 130,000 respondents of 16 years and over

Coverage: $\mathrm{EU}$ is

Topics: income, health, education, housing, demographics and employment characteristics

Accessibility: via EUROSTAT

Information: http://forum.europa.eu.int/irc/dsis/echpanel/info/data/information. $\underline{\mathrm{html}}$

International Social Survey Programme 2005 - Module of work orientations (ISSP)

Design: cross-section, written questionnaires

Sampling: random sample of individuals

Size: I, 500 respondents per country

Coverage: 40 countries world-wide

Topics: role of government, social inequality, family and changing gender roles, work orientations, religion

Accessibility: http://www.gesis.org/en/za/index.htm

Information: http://www.issp.org 
European Values Study I999 (EVS)

Design: cross-section, face-to-face questionnaires

Sampling: random sample of individuals of 16 years and over

Size: in most cases $1.500-2000$ respondents per country

Coverage: 33 European countries

Topics: religion and morality, politics, work and leisure, primary relationsole of government, social inequality, family and changing gender roles, work orientations, religion

Accessibility: http://www.gesis.org/en/za/index.htm

Information: http://www.europeanvalues.nl

International Adult Literacy Survey 1994 (IALS)

Design: cross-section, face-to-face interview

Sampling: representative sample of individuals aged between I6-65

Size: mostly some 3000 respondents per country

Coverage: 22 OECD countries

Topics: adult education, community activities, demographics, educational experience, household information, labour force experience, language background, mathematics, parental information, reading at home or at work, self-reported skills, training and writing at home or at work.

Accessibility:?

Information: http://www.statcan.ca:8096/bsolc/english/bsolc?catno=89-588-XIE

European Union Labour Force Survey 1998- (EULFS)

Design: cross-section, face-to-face, written questionnaire, telephone interview, register data

Sampling: representative sample of households

Size: 7,500 - 75,000 households per country

Coverage: EUis

Topics: education, demographics and employment characteristics

Accessibility: via EUROSTAT

Information: http://europa.eu.int/comm/eurostat/newcronos/reference/sdds/en/ employ/lfs_sm.htm\#top 


\section{Appendix B \\ Relevant questions from \\ EULFS and ECHP}

\section{EULFS 2006 version}

Labour status during the reference week

I

Did any work for pay or profit during the reference week - one hour or more (including family workers but excluding conscripts on compulsory military or community service)

2

Was not working but had a job or business from which he/she was absent during the reference week (including family workers but excluding conscripts on compulsory military or community service)

Was not working because on lay-off

4

Was a conscript on compulsory military or community service

Other (is years or more) who neither worked nor had a job or business during the reference week

Not applicable (child less than Is years old)

\section{Occupation}

ISCO-88 (COM)

$999 \quad$ Not applicable

blank No answer

Involvement of the public employment office at any moment in finding the present job

No

Yes

$9 \quad$ Not applicable

blank No answer 
Full-time / Part-time distinction

I

2

9

blank

I

2

3

2

9

blank

I

2

3

4

9

blank
Full-time job

Part-time job

Not applicable

No answer

\section{Reasons for the part-time work}

Part-time job which was taken because

- person is undergoing school education or training

- of own illness or disability

- looking after children or incapacitated adults

- other personal or family reasons

- person could not find a full-time job

- person did not want a full-time job

- of other reasons

Not applicable

No answer

\section{Permanency of the job}

Person has a permanent job or work contract of unlimited duration

Person has temporary job/work contract of limited duration because:

Not applicable

No answer

Reasons for having a temporary job/contract of limited duration

Person has temporary job/work contract of limited duration because:

- it is a contract covering a period of training (apprentices, trainees, research assistants, etc.)

- person could not find a permanent job

- person did not want a permanent job

- it is a contract for a probationary period

Not applicable

No answer 
Looking for another job and reasons for doing so

$\mathrm{O}$

I

9

blank

I

2

3

4

5

6

7

9

blank

2

3

4

9

O
I
2
3
4
5
6
7

Person is not looking for another job

Person is looking for another job

Not applicable (col.24=3-5,9)

No answer

\section{Person is looking for another job because}

- of risk or certainty of loss or termination of present job

- actual job is considered as a transitional job

- seeking an additional job to add more hours to those worked in present job

- seeking a job with more hours worked than in present job

- seeking a job with less hours worked than in present job

- of wish to have better working conditions (e.g. pay, working or travel time, quality of work)

- of other reasons

Not applicable

No answer

\section{Seeking employment during previous four weeks}

Person has already found a job which will start later within a period of at most 3 months

Person has already found a job which will start in more than 3 months and is not seeking employment

Person is not seeking employment and has not found any job to start later

Person is seeking employment

Not applicable

\section{Duration of search for employment}

Search not yet started

Less than I month

I-2 months

3-5 months

6-II months

I2-I7 months

I8-23 months

24-47 months 
8

9

blank

2

3

4

5

6

7

8

9

blank

3

2

9

blank

4 years or longer

Not applicable

No answer

Main labour status

Carries out a job or profession, including unpaid work for a family business or holding, including an apprenticeship or paid traineeship etc.

Unemployed

Pupil, student, further training, unpaid work experience

In retirement or early retirement or has given up business

Permanently disabled

In compulsory military service

Fulfilling domestic tasks

Other inactive person

Not applicable

No answer

Student or apprentice in regular education during the last four weeks

Has been a student or an apprentice

Person in regular education but on holidays

Has not been a student or an apprentice

Not applicable (child less than I5 years)

No answer

Did you attend any course, seminars, conferences or receive private lessons or instructions outside the regular education system (hereafter mentioned as taught learning activities) within the last four weeks

I $\quad$ Yes

$2 \quad \mathrm{No}$

$9 \quad$ Not applicable (child less than Is years)

blank No answer

Purpose of the most recent taught learning activity

I

Mostly job related (professional) 


\begin{tabular}{l|l}
2 & Mostly personal/social \\
9 & Not applicable \\
blank & No answer
\end{tabular}

optional Monthly (take home) pay from main job

\begin{tabular}{l|l} 
& $\begin{array}{l}\text { The } 8 \text { digits of monthly (take home) pay from main job, } \\
\text { including extra payments monthly paid }\end{array}$ \\
$\begin{array}{l}99999999 \\
\text { blank }\end{array}$ & $\begin{array}{l}\text { Not applicable } \\
\text { No answer }\end{array}$
\end{tabular}




\section{ECHP:}

Q13 Have you had formal training or education that has given you skills needed for your present type of work?

Yes

No

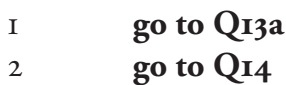

Qiзa How much has this training and education contributed to your present work? Would you say ...

A lot I

A fair amount 2

Not very much

Not at all?

Q14 Do you feel that you have skills or qualifications to do a more demanding job than the one you now have?

Yes I

No 2

Qi6 Apart from (the official language of the country), do you use any other languages in your work?

Yes

I

No

Q30 How satisfied are you with your present job or business in terms of earnings, hours of work, working conditions etc?

Using the scale I to 6 please indicate your degree of satisfaction in each case. Position 'I' means that you are not satisfied at all, and ' 6 ' that you are fully satisfied.

Earnings $\quad$ I-6

Job security I-6

Type of work $\quad$ I-6

Number of working hours I-6

Working times (day time, night time, shifts, etc) I-6

Working conditions/environment I-6

Distance to job/commuting I-6 
QI48 On the whole, how satisfied are you with the education and training you received?

Please use a scale of $\mathrm{I}$ to 6 , position ' $\mathrm{I}$ ' meaning you are not satisfied at all and ' 6 ' meaning that you are fully satisfied.

Degree of satisfaction

$$
\text { I-6 }
$$





\section{Appendix C Comparison of age groups, synthetic cohorts and real cohorts}

In EAG all information on the transition from school to work is based on age groups e.g. the 15-19-year-olds or the 20-24-year-olds. However, using age groups has two important disadvantages. First, educational effects are not separated from labour market experience effects. The problem is that the lowest educated in a particular age group have systematically more labour market experience than the higher educated ones. This follows from the fact that, on average, lower educated school-leavers leave initial education at a younger age. This makes a comparison between the different levels difficult. Second, this method does not take into account that the typical schoolleaving age of a certain educational level differs between countries. In a country like Germany for instance, tertiary education graduates are relatively old, while in Japan they are quite young. Using an age group of $20-24$ would give a stronger underestimation of tertiary education graduates in Germany than in Japan.

To avoid these problems, labour market entry cohorts should be used instead of age groups. The concept of a labour market entry cohort introduces a career perspective on the school-to-work transition, since labour market entry is defined relative to the date of completing one's highest level of education rather than biological age. The 'gold standard' is to sample school-leavers who left education in a particular year (say I or 5 years before the survey). In that case every school-leaver has potentially the same amount of labour market experience. An alternative that approaches this 'gold standard' is to construct synthetic cohorts based on typical graduation ages for the different educational levels. To give an example, if the typical graduation age in France is I9 for ISCED $3 \mathrm{~A}$ and 25 for ISCED $5 \mathrm{~A}$, then one could select the 19-23-yearolds with an ISCED 3 A degree and the 25-29-year-olds with an ISCED 5 A degree to construct a synthetic cohort. ${ }^{1}$

Although in theory the cohort approach is to be preferred above the age group approach, in practice we don't know exactly how much harm is done if we would use age groups. To test this, we performed an analysis on the LFS 2000 ad hoc module on school-to-work transitions. This ad-hoc module focussed on young people under 30 who had left education during a time period of five years before the moment of the survey. As we also have data on the regular LFS of that year, we can compare the

I. See Gangl (2003) for a further elaboration of this approach. 
outcomes on a number of indicators, using the three methods: age groups, synthetic cohorts and real cohorts. Both age groups and synthetic cohorts will be compared with the real cohorts. We will distinguish several age groups to see which age group gives the closest results compared to the real cohort data: 20-24, I5-24 and I5-29 and in the case of occupations 25-29. For all three methods we selected only the 15-29year-olds. As outcome variables we looked at unemployment rates, getting a temporary job, getting a part-time job, working in an elementary occupation (ISCO major group 9), working in a professional occupation or a managerial job (ISCO major group I and 2) and receiving training in the past 4 weeks. For the analyses on characteristics of the job, data were lacking for Finland and Ireland. For training data were lacking for Ireland.

\section{Table C 1}

Comparison of unemployment rates

$\begin{array}{lrrrrr}\text { Country } & 20-24 & 15-24 & 15-29 & \text { synthetic } & \text { real } \\ \text { AT } & 5,7 & 7,3 & 5,7 & 6,2 & 4,1 \\ \text { BE } & 12,2 & 14,1 & 10,7 & 9 & 12,4 \\ \text { DK } & 5 & 5,9 & 5,5 & 4,5 & 4,6 \\ \text { GR } & 26,6 & 28,5 & 22,6 & 25,8 & 31,1 \\ \text { ES } & 20,1 & 22,5 & 19 & 19,6 & 22,2 \\ \text { FIN } & 15,1 & 17 & 13 & 12,9 & 16,5 \\ \text { FR } & 20,4 & 23,5 & 16,8 & 18,1 & 17,8 \\ \text { IRL } & 5 & 6,5 & 5,4 & & 5,5 \\ \text { IT } & 27,6 & 22,5 & 28,9 & 5,1 \\ \text { LU } & 7,1 & 6,5 & 4,8 & 5,9 & 4 \\ \text { NL } & 2,5 & 3,3 & 2,8 & 2,2 & 7,3 \\ \text { PT } & 7,4 & 5,9 & 7,6 & 8,1 \\ \text { SE } & 7,4 & 7,2 & 7,1 & 9,4 \\ \text { UK } & 9 & 9,1 & 8,5 & 7,1 & \\ \text { Squared ifferences } & 9,1 & 10,4 & 139,03 & 74,23 & \\ \text { Correlation } & 42,05 & 61,55 & & & \\ \text { Rank correlation } & 0.98 & & & \\ \end{array}$

The results on unemployment rates show that estimates based on the age group 2024-year-olds yield practically the same results as the 'gold standard' and even better results than the synthetic cohort approach. The sum of squared differences with the estimates based on the real cohort data is quite low and both the correlation and the rank correlation are 0.98 . 
Table C2

Comparison of proportion of workers having a temporary job

$\begin{array}{lrrrrr}\text { Country } & 20-24 & 15-24 & 15-29 & \text { synthetic } & \text { real } \\ \text { AT } & 8,1 & 13,9 & 9,5 & 13,7 & 15,9 \\ \text { BE } & 26,7 & 28 & 18,5 & 20,4 & 24,4 \\ \text { DK } & 19,3 & 19,8 & 11,7 & 12,2 & 14,8 \\ \text { GR } & 25,2 & 27,2 & 21,6 & 24,5 & 28,3 \\ \text { ES } & 63,5 & 67,4 & 55,6 & 57,7 & 66,7 \\ \text { FR } & 43,3 & 46 & 30,7 & 34 & 40,6 \\ \text { IT } & 23,2 & 25,1 & 18,7 & 28,2 & 31,8 \\ \text { LU } & 8,3 & 7,7 & 5,4 & 6,7 & 11,4 \\ \text { NL } & 19,8 & 25,3 & 18,3 & 20,8 & 23,2 \\ \text { PT } & 39,9 & 40,6 & 33,7 & 39,7 & 50,5 \\ \text { SE } & 37,3 & 39,3 & 27,8 & 29,7 & 34,4 \\ \text { UK } & 11,5 & 13,2 & 10,2 & 10,8 & 12,4 \\ \text { Squared differences } & & & & 348,7 \\ \text { Correlation } & 330,23 & 258,47 & 913,75 & & \\ \text { Rank correlation } & 0.96 & & & \end{array}$

The analysis on the proportion of workers in a temporary job also yields good results for the age group approach. Using the $15-24$-year-olds is even better than using the 20-24-year-olds, but the latter group still gives estimates that correlate highly with the real cohort approach. 


\section{Table C 3}

Comparison of proportion of workers having a part-time job

$\begin{array}{lrrrrr}\text { Country } & 20-24 & 15-24 & 15-29 & \text { synthetic } & \text { real } \\ \text { AT } & 9,6 & 9,2 & 12,3 & 9 & 10,7 \\ \text { BE } & 17,5 & 17,8 & 17 & 15,3 & 15,5 \\ \text { DK } & 17,8 & 19,5 & 13,4 & 16,8 & 14,8 \\ \text { GR } & 6,2 & 6,6 & 5,3 & 6,5 & 7,5 \\ \text { ES } & 10,4 & 10,4 & 9,3 & 10,6 & 9,5 \\ \text { FR } & 17,6 & 18,1 & 15,1 & 14,8 & 15,7 \\ \text { IT } & 9,9 & 9,7 & 9,5 & 10,8 & 11,3 \\ \text { LU } & 7,7 & 7,1 & 5,1 & 6,7 & 4,6 \\ \text { NL } & 23 & 28,1 & 27,4 & 27,3 & 4,2 \\ \text { PT } & 4,9 & 4,8 & 4,8 & 4,6 & 19,7 \\ \text { SE } & 18,8 & 20 & 18 & 15,6 & 11,8 \\ \text { UK } & 18,7 & 33,4 & 24,7 & 17,3 & \\ \text { Squared differences } & 107,84 & 512,84 & 185,8 & 62,64 & \\ \text { Correlation } & 0.89 & & & \\ \text { Rank correlation } & 0.91 & & & \\ & & & & \\ \end{array}$

In the analysis on having a part-time job, the synthetic cohort approach is slightly better than the age group approach, but still using the age group of 20-24-year-olds yields estimates very comparable to the real cohort data (correlation and rank correlation 0.89 and 0.91 respectively). 


\section{Table $\mathrm{C}_{4}$}

Comparison of proportion working in an elementary occupation

$\begin{array}{lrrrrr}\text { Country } & 20-24 & 25-29 & 15-29 & \text { synthetic } & \text { real } \\ \text { AT } & 5,7 & 6,8 & 6,4 & 3,6 & 4,3 \\ \text { BE } & 13,3 & 10,9 & 12 & 8,2 & 8,8 \\ \text { DK } & 17 & 8,4 & 14,1 & 13,2 & 10,6 \\ \text { GR } & 5,1 & 4,6 & 5 & 3,6 & 3 \\ \text { ES } & 20,3 & 13,5 & 17,6 & 12,3 & 13,9 \\ \text { FR } & 10,9 & 6,9 & 8,5 & 7,7 & 7,9 \\ \text { IT } & 8,7 & 7,6 & 8,1 & 5,7 & 5,8 \\ \text { LU } & 8,3 & 8 & 7,9 & 6,3 & 3,9 \\ \text { NL } & 8,2 & 6,1 & 7,9 & 5,6 & 6,3 \\ \text { PT } & 13,5 & 11,3 & 13,4 & 14 & 12 \\ \text { SE } & 6,2 & 4,3 & 5,8 & 4 & 5,9 \\ \text { UK } & 8,9 & 6,3 & 9,1 & 7 & 6,1 \\ \text { Squared differences } & & & & \\ \text { Correlation } & 159,1 & 42,4 & 79,77 & 25,25 & \\ \text { Rank correlation } & & 0.83 & & & \end{array}$

In the case of the proportion of young people working in an elementary occupation, the synthetic cohort approach gives the best results, although the difference with the age group approach is not large. Using the age group 20-24-year-olds leads to an overestimation of the proportions working in elementary occupations. Using the age group of 25-29-year-olds yields better results (correlation and rank correlation 0.83 and 0.68 respectively). 


\section{Table $\mathrm{C}_{5}$}

Comparison of proportion working in a managerial or professional occupation

$\begin{array}{lrrrrr}\text { Country } & 20-24 & 25-29 & 15-29 & \text { synthetic } & \text { real } \\ \text { AT } & 7,1 & 14,5 & 10,7 & 16,3 & 12,8 \\ \text { BE } & 19,4 & 27,5 & 23,9 & 34,8 & 31,7 \\ \text { DK } & 3,3 & 15,5 & 10,3 & 16,3 & 12,6 \\ \text { GR } & 7,2 & 16,8 & 12,3 & 17,6 & 17,7 \\ \text { ES } & 5,7 & 15,5 & 10,5 & 18,5 & 17,3 \\ \text { FR } & 4,3 & 13,9 & 10,5 & 16,4 & 14,2 \\ \text { IT } & 3,8 & 7,6 & 6 & 11,4 & 11,3 \\ \text { LU } & 8,3 & 24 & 17,9 & 31,3 & 30,3 \\ \text { NL } & 11,4 & 26,3 & 19,5 & 30,9 & 24,6 \\ \text { PT } & 5,2 & 13,5 & 9 & 11,1 & 16,5 \\ \text { SE } & 8,7 & 20,9 & 15,8 & 21,1 & 20,8 \\ \text { UK } & 17,6 & 31,4 & 20,5 & 31,6 & 34 \\ \text { Squared differences } & & & & \\ \text { Correlation } & & 105,12 & 630,99 & 117,55 & \\ \text { Rank correlation } & 1870,64 & 0.94 & & & \\ & & 0,91 & & & \\ \end{array}$

When analysing the proportion working in a managerial or professional occupation, using the age group of 25-29-year-olds yields the best results compared with the real cohort data (correlation and rank correlation 0.94 and 0.9I respectively). 
Table C6

Comparison of proportion of workers receiving training in the past four weeks

$\begin{array}{lrrrrrr}\text { Country } & 15-24 & 20-24 & 25-29 & 15-29 & \text { synthetic } & \text { Real } \\ \text { AT } & 14 & 10,3 & 10,7 & 12,2 & 16,9 & 19,2 \\ \text { BE } & 9,5 & 9,5 & 11,2 & 10,6 & 13 & 14,6 \\ \text { DK } & 14 & 15,3 & 16,3 & 15,3 & 20,2 & 25,7 \\ \text { GR } & 1,2 & 1,4 & 0,8 & 1 & 1,8 & 0,9 \\ \text { ES } & 8,3 & 8,3 & 6,9 & 7,6 & 10,8 & 2,2 \\ \text { FR } & 6,5 & 5,7 & 3,6 & 4,6 & 5,6 & 6,9 \\ \text { IT } & 4,4 & 4,9 & 4,5 & 4,4 & 6,5 & 10,4 \\ \text { LU } & 0 & 0 & 4,2 & 2,7 & 6,3 & 8,8 \\ \text { NL } & 16,5 & 15,2 & 14,1 & 15 & 18 & 16,7 \\ \text { PT } & 6,2 & 7,3 & 6,5 & 6,3 & 7,2 & 6,6 \\ \text { FIN } & 13,5 & 14,9 & 20,2 & 17,1 & 18,9 & 28,7 \\ \text { SE } & 11,5 & 12,2 & 16,5 & 14,5 & 15,9 & 17,1 \\ \text { UK } & 46,9 & 31,6 & 19,5 & 34,6 & 33,5 & 39,3\end{array}$

Finally, in the analysis on training, all alternative methods give an underestimation of the proportion of workers receiving training compared to the 'gold standard'. It is not quite clear what causes this. Nevertheless the correlation between the different methods is very high and the rank order of countries is not seriously affected if one uses the age group or synthetic cohort approach. Although the latter yields the best results, using the age group of $15-29$ also yields very good results (correlation and rank correlation 0.92 and 0.87 respectively).

We conclude that using data based on age groups instead of school-leavers cohorts does not yield different results. In most case both the absolute and relative differences are quite small. In most cases it is best to age the age group of 20-24-year-olds. When analyses on occupations are concerned, it is best to take an older age group, namely the 25-29-year-olds. Finally, for the training variables it is best to take the 15-29-yearolds. 



\section{Appendix D \\ Comparison of unemployment rates for lower educated and higher educated}

We used the EULFS ad hoc module to compare unemployment rates for lower and higher educated using the age group approach and the cohort approach. Based on the analyses in appendix c, we already know that using age groups yields similar results as using the cohort approach. However, these results relate to outcomes for the total group and there are good arguments why the age group might be particularly problematic when comparing lower educated and higher educated. As the lower educated in a particular age group have on average more work experience than the higher educated, the differences in labour market position might be underestimated. This would show up in particular in the unemployment rates.

Table D1

Comparison of unemployment rates of lower educated (ISCED 0-2) versus higher educated (ISCED 3-6) using the age group 20-24-year-olds or the school-leaver cohort approach

\begin{tabular}{|c|c|c|c|c|c|c|}
\hline Country & $\begin{array}{r}\text { isced 0-2 } \\
20-24\end{array}$ & $\begin{array}{r}\text { isced 3-6 } \\
20-24\end{array}$ & $\begin{array}{r}\text { ratio } \\
20-24\end{array}$ & $\begin{array}{r}\text { isced 0-2 } \\
\text { cohort }\end{array}$ & $\begin{array}{r}\text { isced 3-6 } \\
\text { cohort }\end{array}$ & $\begin{array}{r}\text { ratio } \\
\text { cohort }\end{array}$ \\
\hline AT & 13,5 & 4,6 & 2,934783 & 13,5 & 2,6 & 5,192308 \\
\hline $\mathrm{BE}$ & 22,2 & 9,7 & 2,28866 & 31,5 & 9,6 & 3,28125 \\
\hline DK & 5,1 & 4,2 & 1,214286 & 3,4 & 4,9 & 0,693878 \\
\hline GR & 22,8 & 28,2 & 0,808511 & 29 & 31,4 & 0,923567 \\
\hline ES & 19,8 & 20,3 & 0,975369 & 27,5 & 20,1 & 1,368159 \\
\hline FIN & 23,8 & 13,8 & 1,724638 & 35 & 14,8 & 2,364865 \\
\hline FR & 34 & 16,3 & 2,08589 & 37,1 & 14 & 2,65 \\
\hline IT & 27,6 & 27,6 & 1 & 33,9 & 26,3 & 1,288973 \\
\hline NL & 4,2 & 1,7 & 2,470588 & 5,9 & 3,5 & 1,685714 \\
\hline PT & 7,5 & 7,1 & 1,056338 & 8 & 6,4 & 1,25 \\
\hline SE & 13,2 & 8 & 1,65 & 15,3 & 6,7 & 2,283582 \\
\hline $\begin{array}{l}\text { Average } \\
\text { difference }\end{array}$ & $-4,2 \%$ & $+0,1 \%$ & & & & \\
\hline RISCED 0-2 & 0.97 & & & & & \\
\hline RISCED 3-6 & & 0.99 & & & & \\
\hline Rratio & & & 0.84 & & & \\
\hline
\end{tabular}


Indeed, we find some evidence that in most countries the estimates of the unemployment of the lower educated based on the age group approach yields an underestimation of the 'real' unemployment rate of some $4 \%$. For the higher educated group, the differences are negligible. Of course this also means that the ratio's will be underestimated. However the differences between the countries are not very much affected by using the age group approach, given the rather high correlations between the estimates of the two methods. 


\section{Appendix E \\ Comparison of two measures of graduation rates}

Table eI compares two measures for upper secondary education rates: one based on counts of first-time graduates in upper secondary education regardless of age per Ioo people at the typical graduation age and the other on percentage of 20-24-year-olds not in education without an upper secondary education degree. In an ideal world these should more or less sum up to Ioo\%.

Table e1

Apparent upper secondary education rates and \% of 20-24-year-olds not in education without an upper secondary education degree

\begin{tabular}{lrr} 
OECD countries & $\begin{array}{r}\text { Apparent upper secondary } \\
\text { education rates }\end{array}$ & $\begin{array}{r}\text { \% of 20-24-year-olds not in } \\
\text { education without an upper }\end{array}$ \\
Czech Republic & 88,14 & 5,9 \\
Denmark & 85,85 & 9,8 \\
Finland & 84,31 & 9,7 \\
France & 80,90 & 14,3 \\
Germany & 96,87 & 13,9 \\
Greece & 95,94 & 17,7 \\
Hungary & 87,44 & 12,3 \\
Iceland & 78,66 & 29,2 \\
Ireland & 90,74 & 13,7 \\
Italy & 80,80 & 24,6 \\
Luxembourg & 70,59 & 9,2 \\
Mexico & 36,00 & 67,9 \\
Norway & 91,68 & 4,3 \\
Poland & 85,57 & 6,4 \\
Slovak Republic & 56,46 & 4,4 \\
Spain & 66,86 & 32,6 \\
Sweden & 75,88 & 9,8 \\
Switzerland & 90,09 & 10,3 \\
Turkey & 40,81 & 52,9 \\
United States & 73,26 & 12 \\
correlation & & $-0,75$ \\
rank correlation & & $-0,28$ \\
Source: EAG 2005 & & \\
& & 9,8 \\
\hline
\end{tabular}


Although the two methods give estimates that correlate quite highly $(\mathrm{r}=-0.75)$, they don't overlap very well. The rank correlation is even very low due to the strange results for some countries. In the Slovak Republic, Sweden and the United States for instance we find apparent upper secondary graduation rates that are well below the level that would have been expected given the proportion of 20-24-year-olds not in education and without an upper secondary education degree. And conversely, Germany and Greece show upper secondary graduation rates that are well above the level that would have been expected given the proportion of 20-24-year-olds not in education and without an upper secondary education degree. It is not quite clear what causes these differences. To be on the safe side, it is probably best to treat both measures as not completely accurate, and therefore use both as complementary measures of the upper secondary graduation rates.

\section{Table e2}

Apparent Tertiary-type A graduation rates and \% of 25-34-year-olds with Tertiary-type A degree

\begin{tabular}{llr} 
OECD countries & Tertiary-type A graduation rates (2002) & $\begin{array}{r}\text { 25-34-year-olds with } \\
\text { Tertiary-type degree }\end{array}$ \\
\hline Australia & 45,4 & 25 \\
Austria & 18,0 & 7 \\
Czech Republic & 14,9 & 12 \\
Finland & 45,4 & 21 \\
France & 24,8 & 19 \\
Germany & 19,2 & 13 \\
Hungary & 37,2 & 15 \\
Iceland & 41,2 & 23 \\
Ireland & 31,1 & 23 \\
Italy & 22,7 & 12 \\
Japan & 33,8 & 25 \\
Poland & 41,5 & 16 \\
Slovak Republic & 23,0 & 11 \\
Spain & 33,5 & 25 \\
Sweden & 32,7 & 22 \\
Switzerland & 17,9 & 17 \\
United Kingdom & 35,9 & 23 \\
correlation & & 0,61 \\
rank correlation & & 22 \\
Source: EAG 2004 & & 23 \\
& & 23 \\
\hline
\end{tabular}

A more or less similar story holds for the two indicators for Tertiary-type A graduation rates. Unfortunately we could not use the age group of 30-34-year-olds here as these data were not published in EAG, so we had to use the 25-34-year-olds instead. We can note a number of countries that have a more or less comparable proportion of 25 - 
34-year-olds with a Tertiary-type A degree (around 23\%) but quite different apparent graduation rates: around $43 \%$ for Australia, Finland and Iceland while only some $33 \%$ in Ireland, Japan, Spain, Sweden and the United Kingdom. Or contrast Germany and Switzerland against Hungary and Poland. All four countries have a low proportion of 25-34-year-olds with a Tertiary-type A degree (around I5\%) but quite different apparent graduation rates: below 20\% in Germany and Switzerland and around $40 \%$ in Hungary and Poland.

Again it is not quite clear what causes these differences and to be on the safe side, it is probably best to treat both as complementary measures of the Tertiary-type A graduation rates. 
